\title{
Green and Sustainable Chemistry in Practice: Development and Industrialization of a Novel Process for Polycarbonate Production from $\mathrm{CO}_{2}$ without Using Phosgene
}

\author{
Shinsuke FukUOKa, ${ }^{1, \dagger}$ Masahiro ToJo, ${ }^{2}$ Hiroshi HaCHIYA, ${ }^{3}$ \\ Muneaki AmInAKA, ${ }^{3}$ and Kazumi HASEgAwA ${ }^{3}$ \\ ${ }^{1}$ New Business Development, Asahi Kasei Corporation, Kojima-Shionasu, Kurashiki 711-8510, Japan \\ ${ }^{2}$ Central Research \& Development Laboratories, Asahi Kasei Corporation, 2-1 Samejima, Fuji 416-8501, Japan \\ ${ }^{3}$ Technology Licensing Department, Asahi Kasei Chemicals Corporation, Kojima-Shionasu, Kurashiki 711-8510, Japan
}

(Received October 27, 2006; Accepted November 22, 2006; Published January 16, 2007)

\begin{abstract}
This review focuses on the world's first process succeeded in development and industrialization by Asahi Kasei Corp. for producing an aromatic polycarbonate (PC) using $\mathrm{CO}_{2}$ as starting material. ${ }^{1}$ The carbonate group of PC links directly to the residual aromatic groups of the bisphenol. Until Asahi Kasei's new process is revealed, all of carbonate groups of PC in the world were derived from CO as starting material. Furthermore, more than about $90 \%$ of PC has been produced by so-called "phosgene process", and the PC contains Cl-impurities. It needs to use not only highly toxic and corrosive phosgene made from $\mathrm{CO}$ and $\mathrm{Cl}_{2}$ as a monomer, but also very large amounts of $\mathrm{CH}_{2} \mathrm{Cl}_{2}$ and water, and needs to clean a large amount of waste water. The new process enables high-yield production of the two products, $\mathrm{Cl}$-free and high-quality $\mathrm{PC}$ and high-purity monoethylene glycol (MEG), starting from ethylene oxide (EO), by-produced $\mathrm{CO}_{2}$ and bisphenol-A. PC produced by the new process has many excellent properties compared with conventional PCs. The new process not only overcomes drawbacks in the conventional processes, but also achieves resource and energy conservation. The reduction of $\mathrm{CO}_{2}$ emissions $(0.173 \mathrm{t} / \mathrm{PC} 1 \mathrm{t})$ is also achieved in the new process, because all $\mathrm{CO}_{2}$ is utilized as the component consisting main chains of the products. The newly constructed commercial plant of Chimei-Asahi Corp. (Taiwan), a joint venture between Asahi Kasei Corp. and Chi Mei Corp., has been successfully operating at full-production since June 2002. The initial capacity (PC:50,000 t/y) is now increased to $150,000 \mathrm{t} / \mathrm{y}$. A typical example of the Green and Sustainable Chemistry (GSC) contributing to society and mankind has been realized. [doi:10.1295/polymj.PJ2006140]

KEY WORDS Polycarbonate from $\mathrm{CO}_{2}$ / Without Using Phosgene / EO / Cl-Free PC / HighPurity MEG / Reduction of $\mathrm{CO}_{2}$ Emissions / Realized GSC /
\end{abstract}

An aromatic polycarbonate based on bisphenol-A (hereafter usually abbreviated as PC) has been widely employed as the most largely amounts consumed engineering plastic in various applications basic to the modern life style including automobiles, mobile phones, notebook type personal computers, cameras \& video cameras, electric \& electronic appliances, office equipments, life \& living goods, and sheets, etc. Especially, $\mathrm{PC}$ is important as an indispensable resin for optical disks of music or data and image storage, such as CDs and DVDs. Recently PC has become more familiar to people, because a lot of people touch PC many times in a day through handling their mobile phones, which housings and buttons are made of PC. The reasons for the largest consumption and highest growth (more than 10\% per year constantly) of PC are excellent properties such as outstanding impact resistance, transparency, heat resistance, and dimensional stability. In spite of the wide use, only four grades distinguished by the melt viscosities have been produced as the commercial products of PC. These are disk grade, low viscosity grade with high melt index (MI), middle viscosity grade with middle MI and high viscosity grade with low MI. Therefore, it is preferred that a process can produce all these grades.

About 2.7 million tons of PC are produced annually worldwide, and until 2002 all production used carbon monoxide (CO) as starting material. The vast majority of $\mathrm{PC}$ has been produced in the phosgene process where $\mathrm{CO}$ and chlorine are combined to form phosgene, a highly toxic gas and its production and use in factories have been very severely restricted as a chemical weapon worldwide.

The development and industrialization of a new process for producing a widely used important polymeric material by innovative concepts and technologies should contribute to the progress of polymer science and technology. The contribution should become

${ }^{\dagger}$ To whom correspondence should be addressed (Tel: +81-86-458-3347, Fax: +81-86-458-3349, E-mail: fukuoka.sf@om.asahi-kasei.co.jp). 
larger if the process produces the polymeric material having higher quality and physical and chemical properties than the conventional materials, moreover if the process is safer, environmentally benign and economical than the conventional processes and thus it is very useful to society and mankind. This is a matter of course, since one of the important mission of the polymer science and technology is to contribute to mankind by offering the useful polymeric materials, which can raise our human living levels more conveniently, more comfortably, more safely and securely, etc.

Asahi Kasei's novel process for producing high quality $\mathrm{PC}$ using $\mathrm{CO}_{2}$ as starting material without using highly toxic phosgene and $\mathrm{CH}_{2} \mathrm{Cl}_{2}$ must be one of such processes contributing for the progress of the polymer science and technology.

In historically, a lot of aromatic polycarbonates were investigated in the 1950's. In these investigations, Schnell (Bayer AG:) and Fox (General Electric Co.) reached independently the same conclusion that the polycarbonate derived from 2,2-bis-(4-hydroxyphenyl)-propane (hereafter usually abbreviated as bisphenol-A) has excellent mechanical and electrical properties and should become an important plastic as an industrial material. ${ }^{2-6}$

This bisphenol-A polycarbonate (BPA-PC) was first produced industrially in Germany by Bayer AG (1958) and then in USA by Mobay Chemicals Corp. (1960) and by General Electric Co. (GE) (1960) respectively. ${ }^{7}$ The industrialized processes in these companies have used phosgene and bisphenol-A as raw materials, and thus have been called "phosgene process."

In Japan, Teijin Chemicals Ltd. (1960), Idemitsu Petrochemicals Co. (1960) and Mitsubishi Gas Chemical Co. (1961), have industrialized BPA-PC by using the "phosgene process." Then, Mitsubishi Chemical Co. (1975) has begun producing PC by introducing the phosgene process from Idemitsu, and lastly Dow Chemical Co. (1985) has begun producing PC by the phosgene process. ${ }^{8}$ Since then, all PCs (more than one million tons in a year) in the world have been produced by the above 6 company groups (Bayer, GE, Teijin, Mitsubishi, Idemitsu, Dow) until Asahi Kasei's new process has been commercialized in 2002.

Bayer developed another process so-called "transesterification process" or "melt process" using transesterification reaction in the melt-state between bisphenol A and diphenyl carbonate (DPC) prepared from phosgene, phenol and $\mathrm{NaOH}$, and industrialized the process in the early 1960s. Teijin Chemicals and Mitsubishi Gas Chemicals introduced the "transesterification process" by licenses from Bayer and industrialized in 1964 and 1965 respectively. ${ }^{8}$

However, all these old-type "transesterification processes" faded out by the late 1970s. The reasons for the fade-out of the old-type "transesterification processes" are well known as follows. Generally, a transesterification process requires a complicated agitating polymerization reactor which can agitate the very high viscous polymer at high temperatures $\left(>300^{\circ} \mathrm{C}\right)$ under high vacuum without any leaking air into the reactor, however, such a reactor had not been available. Moreover, the PCs produced by these old-type transesterification processes were yellowish colored due to side reactions under the severe conditions. Namely, these processes could not produce the nearly colorless products, key property of PC. In addition, the molecular weight control in these transesterification processes was difficult compared with the phosgene process using a molecular weight control agent to cap terminal groups of the polymer. Furthermore, these transesterification processes using mechanical agitation could not produce the high viscosity grade of PCs, since such mechanical agitation could not attain the sufficient surface renewal of the polymerizing material due to the ultra high melt viscosity. The effective surface renewal of the polymerizing material is necessary to progress polymerization to the high viscosity grade by removing the phenol produced and presented inside of the melt material. Hence, these processes were not suitable for producing a broad product range of PC. ${ }^{9,10}$ The difficulties in the molecular weight control and in the production of the high viscosity grade of PCs are present even now in the transesterification process.

Accordingly, the industrial production of the BPAPC has been continued only by the phosgene processes of the only above 6 company groups for more than 25 years since the fade out of the old type transesterification processes by the late 1970 's. ${ }^{11}$

In such circumstances, our R \& D to develop an innovative process for producing PC without using phosgene, that is, non-phosgene PC process, started in 1977.

Our strong will was to attain the mission that contributes to society and mankind by creating and practicing a "benign process to the earth." Our mission is in agreement with the principles of "The Green and Sustainable Chemistry Network (GSCN)" organized more than 25 years later. GSCN consists of many academic and industrial societies in Japan including The Society of Polymer Science, Japan, and has the principles of promoting research and development for the Environment and Human Health and Safety, through the innovation of Chemistry. Asahi Kasei's researchers and engineers have made substantial endeavors to develop new non-phosgene process for the production of PC for about 25 years. As a result, we have succeeded in developing the innovative non-phosgene 


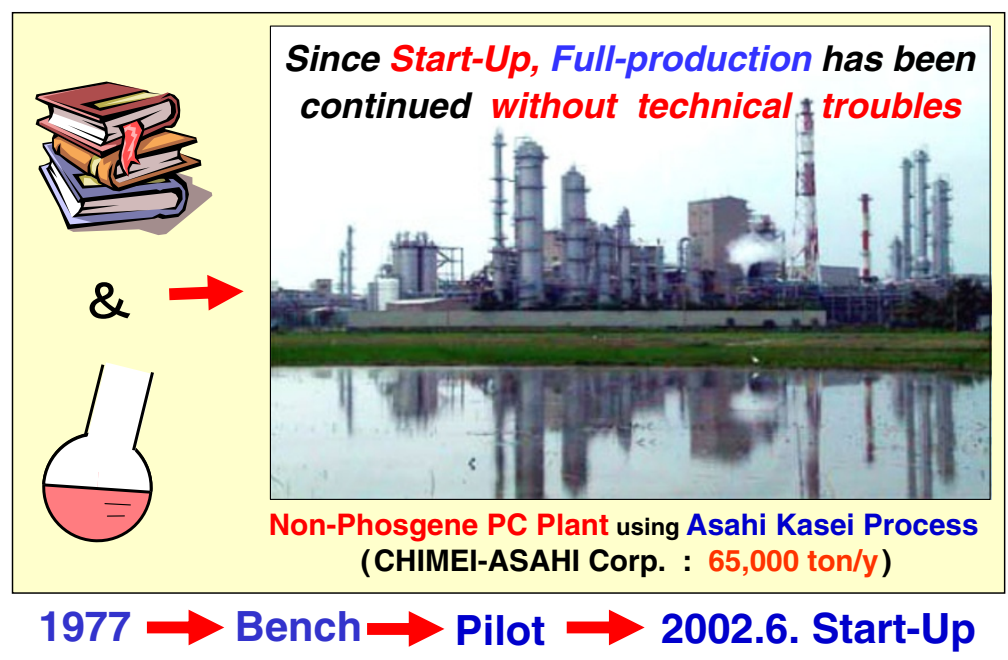

Figure 1. From basic research to success in industrialization.

process for producing PC from $\mathrm{CO}_{2}$ at the pilot stage until in 1998 and in industrialization of the process in 2002 shown in Figure 1.

In the new process, the carbonyl groups consisting the carbonate chains of PC come from $\mathrm{CO}_{2}$.

This is the world's first polycarbonate production process using $\mathrm{CO}_{2}$ as starting material, in contrast to all other conventional processes using $\mathrm{CO}$ as starting material.

This review describes the innovative and inventive process for producing PC including not only the newly developed creative polymerization methods but also how to produce the monomer from $\mathrm{CO}_{2}$ industrially, which monomer production step constitutes very important part of the new process since the monomer, diphenyl carbonate (DPC), has not been available commercially.

\section{CONVENTIONAL PHOSGENE PROCESS AND DRAWBACKS}

General Electric Company initially commercialized PC production using bisphenol-A and phosgene in the presence of pyridine (Pyridine Method). All phosgene processes now involved interfacial polycondensation with two immiscible solvents, in which the reaction of di-sodium salts of bisphenol-A solved in water with phosgene solved in a chlorinated organic solvent such as $\mathrm{CH}_{2} \mathrm{Cl}_{2}$ is carried out under strong agitation. Usually, the reaction is carried out in two steps. In the first step, phosgenation of di-sodium salts of bisphenol-A mainly produces chloroformates of bisphenol-A, and in the following second step, a catalyst selected from tertiary amines or quaternary ammonium salts is added and polycondensation of the chloroformates is carried out to produce $\mathrm{PC}$. $\mathrm{CH}_{2} \mathrm{Cl}_{2}$ is especially preferred for its very high solubility in $\mathrm{PC}$ as the chlorinated

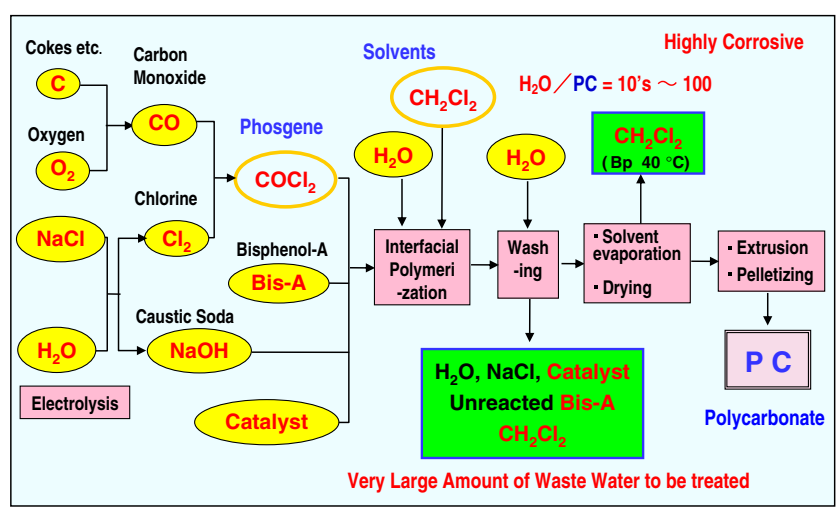

Figure 2. Phosgene process for PC production.

hydrocarbon solvent, the produced PC is obtained as a solution of the chlorinated hydrocarbon solvent. In the phosgene process, a mono hydroxyl aromatic compound such as phenol and tert-butyl phenol is used as a molecular weight control agent to cap the terminal groups of the polymer.

However, it is well known that the phosgene process (see Figure 2) entails a number of drawbacks in environmental and economical terms as follows:

(1) A large quantity (more than 0.43 ton/PC 1 ton) of very dangerous and corrosive phosgene must be used as monomer. Phosgene is designated as a chemical weapon, and thus the production and use have been severely restricted worldwide.

(2) It is necessary to use a very large quantity (more than 10 times by weight of the $\mathrm{PC}$ to be produced) of $\mathrm{CH}_{2} \mathrm{Cl}_{2}$ as a polymerization solvent. Methylene chloride is a low boiling-point solvent with an exposure limit reflecting its carcinogenic properties (IARC classification: group-2B, possibly carcinogenic to humans; EPA classification: group-B2, probable human carcinogen). 


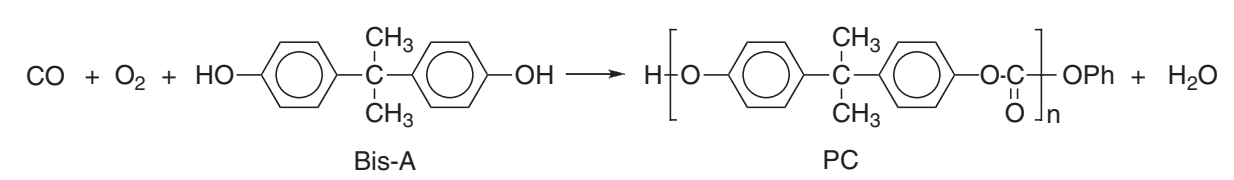

Scheme 1. Oxidative carbonylation of bisphenol-A.

(3) A very large quantity of waste water containing organic compounds must be treated to the environmentally allowable level before discharging from the factory. The process requires a very large quantity of water (more than 10 times by weight of the PC to be produced) in the polymerization step. In addition, a very large quantity of water (usually more than 10 times by weight of the PC produced, or more than 100 times by weight in the case of production of optical use grade) is used for washing and purification of the obtained $\mathrm{CH}_{2} \mathrm{Cl}_{2}$ solution of $\mathrm{PC}$ to remove the contaminants, such as the $\mathrm{NaCl}$ produced, the unreacted sodium salt of bisphenol-A, the low molecular weight oligomers, and polymerization catalyst used etc. After the polymerization and purification steps, the water layer is separated from the $\mathrm{CH}_{2} \mathrm{Cl}_{2}$ layer by the phase separation step. However, the water layer contains much $\mathrm{CH}_{2} \mathrm{Cl}_{2}$ dissolved in water $(20 \mathrm{~g} / \mathrm{L})$ along with other contaminants.

(4) It is very difficult to prevent completely the release of the $\mathrm{CH}_{2} \mathrm{Cl}_{2}$ to the atmosphere due to its low boiling point $\left(40^{\circ} \mathrm{C}\right)$.

(5) It is easy for corrosion of the equipments to occur due to $\mathrm{Cl}_{2}$ and chloride anion. Almost all systems (such as phosgene production, interfacial polymerization, washing and purification by water, recovering of $\mathrm{CH}_{2} \mathrm{Cl}_{2}$ from the solvent containing water, drying the wet powder containing $\mathrm{CH}_{2} \mathrm{Cl}_{2}$, and palletizing of powder polymer containing $\mathrm{CH}_{2} \mathrm{Cl}_{2}$ ) contain and contact with chloride compounds, $\mathrm{Cl}_{2}$, hydrochloric acid and aqueous solution of $\mathrm{NaCl}$, which are highly corrosive to the metallic materials. This means that expensive metallic materials are necessary for construction of the factory, and furthermore the maintenance costs of the facilities increase.

(6) The raw materials, $\mathrm{Cl}_{2}$ and $\mathrm{NaOH}$ produced by electrolysis of aqueous $\mathrm{NaCl}$ and much electric power, are consumed and converted to $\mathrm{NaCl}$ to become salt water waste leading to greater running cost of the production.

(7) The chloride impurities $\left(\mathrm{CH}_{2} \mathrm{Cl}_{2}, \mathrm{NaCl}\right.$, etc.) are inevitably containing in the product $\mathrm{PC}$ to cause deterioration of the properties such as heat resistance, color tone, etc.

\section{TECHNICAL BARRIERS TO BE OVERCOME}

The phosgene process has a lot of drawbacks envi- ronmentally and economically as described above. In order to solve these problems and to develop a safer alternative process, there has been much investigations for long years. One of these attempts is oxidative carbonylation of bisphenol-A by $\mathrm{CO}$ and oxygen as shown in Scheme 1, which attempt was firstly disclosed by GE's patents in $1978 .^{12}$

This process may be most preferable, because this reaction introduces $\mathrm{CO}$ group directly on to the bisphenol-A group accompanying with by-production of $\mathrm{H}_{2} \mathrm{O}$. However, this reaction needs a precious palladium catalyst and a very complex co-catalyst to make progress the red-ox reaction and a large amount of good solvent for $\mathrm{PC}$ such as $\mathrm{CH}_{2} \mathrm{Cl}_{2}$. Furthermore, use of a lot amount of the dehydrating agents such as molecular sieves is necessary, since product hydrolysis by the by-produced $\mathrm{H}_{2} \mathrm{O}$ occurs easier than the desired reaction. It is also problem that the yield and selectivity are not so high, especially based on CO. Furthermore, it is too difficult to separate the catalyst and co-catalyst without any loss and obtain a clear high-pure PC containing none of impurities derived from these catalysts and having nearly same properties as commercial PC. Molecular weight control is also difficult in this process.

In the commercial production of a polymer, it is most important to produce a polymer having good properties with pre-determined range of molecular weight at low cost. Especially, it is necessary for a new process that the production cost is lower or at least same comparing with the conventional process.

Although many attempts to improve the oxidative carbonylation process have been proposed ${ }^{13}$ since the disclosure by GE in 1978, this process seems too difficult to be commercialized due to the above reasons.

So what kind of the non-phosgene process for producing PC is possible?

With increasing the consumption of PC in the early 1990s, the environmental and cost problems of the phosgene process have become more serious and urgently require solutions. As a result, a lot of attempts to overcome the problems have been appeared in the patents. Attention has been directed to improving the old-type transesterification method and devising a new non-phosgene process shown in Figure 3.

However, there have been a lot of technical barriers to be overcome in order to solve the problems of the old-type transesterification method and to succeed in 


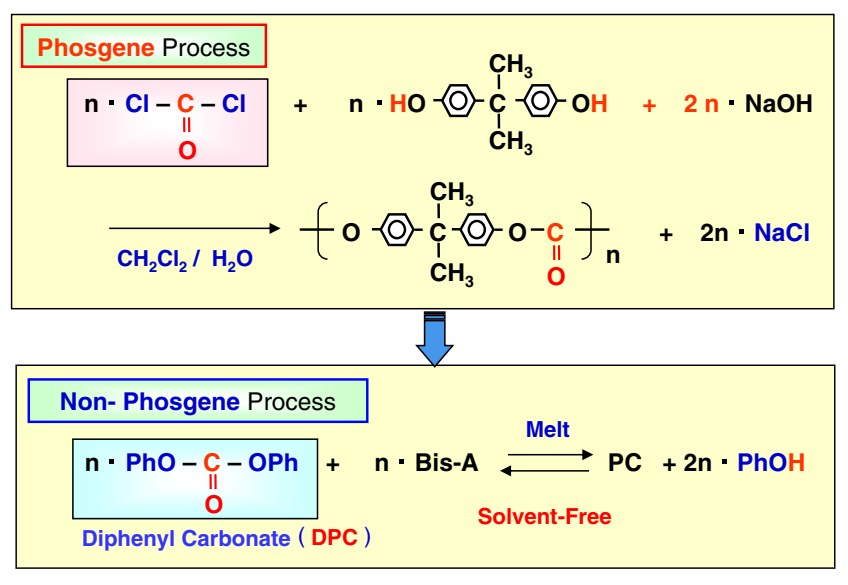

Figure 3. Attempt to non-phosgene PC process.

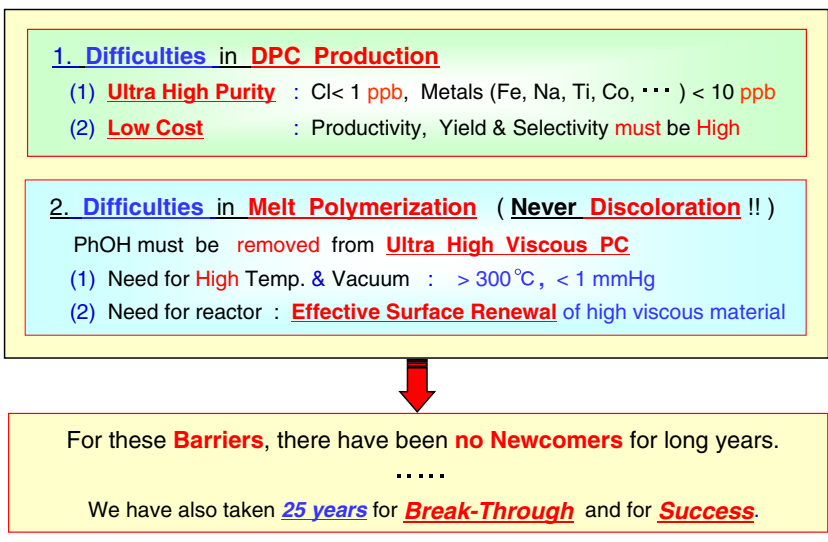

Figure 4. Technical barriers in non-phosgene PC process.

development as a new non-phosgene process. The barriers in the non-phosgene process being especially difficult to be overcome exist in both the production step for the safe monomer of diphenyl carbonate (DPC) to replace phosgene and the polymerization step to produce polycarbonate as shown in Figure 4.

\section{A. Difficulties in the DPC Production Step.}

(1) Even low pure DPC is not available commercially, because DPC has not been produced industrially. Therefore, how to produce DPC is the first consideration. The process must produce ultra high pure DPC. Especially, the contents of halogen impurities and metals impurities in DPC must be extremely low, for example, Cl-content must be less than $1 \mathrm{ppb}$, and total content of metals ( $\mathrm{Fe}, \mathrm{Na}, \mathrm{Ti}, \mathrm{Co}$, etc.) must be less than $10 \mathrm{ppb}$.

(2) Such ultra high pure DPC must be obtainable at lower costs than by the conventional process such as reaction of phosgene with phenol. Productivity, yield and selectivity of DPC must thus be high.

\section{B. Difficulties in the Polymerization Step.}

The equilibrium of the transesterification reaction

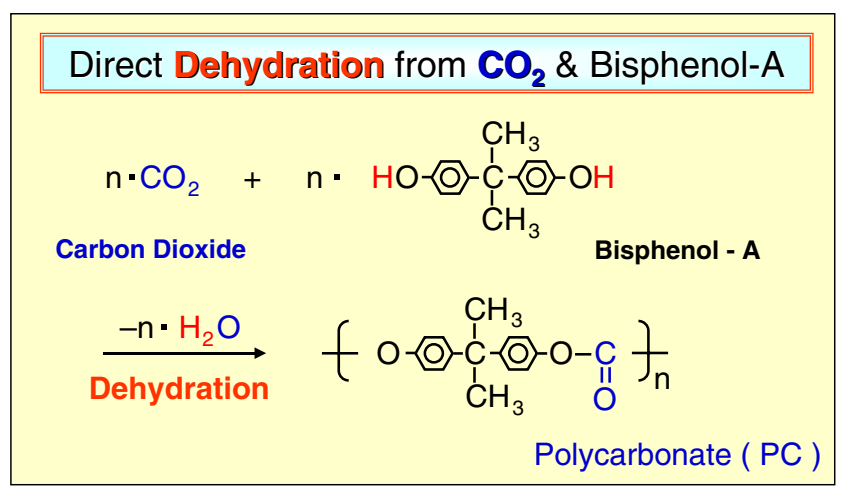

Figure 5. Ideal process for PC production.

to produce $\mathrm{PC}$ favors the raw materials side, therefore, in order to make progress the reaction, the phenol produced by the reaction and present in the molten ultra high viscous polymer must be removed efficiently from the polymer surface. Thus,

(1) To reduce the ultra high viscosity and to make progress the polymerization, more and more severe conditions $\left(>300^{\circ} \mathrm{C},<133 \mathrm{~Pa}\right)$ are necessary as proceeding the reaction. These severe conditions would cause discoloration being fatal defect for transparency and clearness of PC.

(2) A new type polymerization reactor, which enables effective surface renewal of the ultra high viscous polymer under not so severe conditions, is necessary.

Although many attempts to overcome the above difficulties of $A$ and $B$ have been done until now, success has been limited because these technological barriers are extremely too hard and tough to overcome. Except for Asahi Kasei's process, one process developed by GE group using $\mathrm{CO}$ as a staring material and conventional twin-screw type polymerization apparatus has been commercialized. ${ }^{11,14,15,37 a}$

\section{ASAHI KASEI'S GREEN AND INNOVATIVE PROCESS FOR PRODUCING PC: CLOSEST TO THE IDEAL PROCESS}

If it were possible industrially that the direct dehydration reaction between $\mathrm{CO}_{2}$ and bisphenol-A to produce PC as shown in Figure 5, it would be the ideal process for PC production. However, unfortunately, it is impossible to practice the ideal process by today's industrial chemical technology.

As shown in Figure 6, in the Asahi Kasei's new process, two important products, high-quality polycarbonate (PC) and high-purity monoethylene glycol (MEG), are produced in high yields respectively from three starting materials, ethylene oxide (EO), $\mathrm{CO}_{2}$, and bisphenol-A, in which $\mathrm{EO}$ and bisphenol-A are industrially mass-produced and $\mathrm{CO}_{2}$ is also by-produced largely in the world. 


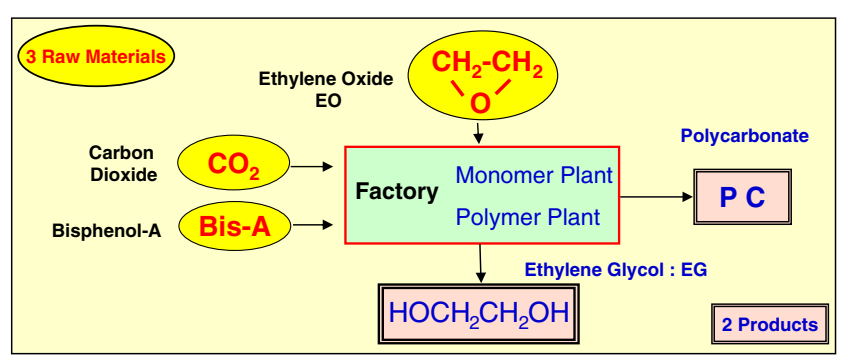

\begin{tabular}{|c|}
\hline Formal Total Schemes ( Actually, No Water ) \\
\hline Horizontal : $\mathrm{CO}_{2}+$ Bis-A $\longrightarrow$ P C $+\left(\mathrm{H}_{2} \mathrm{O}\right):$ Ideal PC Process \\
\hline Vertical $: \mathrm{EO}+\left(\mathrm{H}_{2} \mathrm{O}\right) \longrightarrow$ E G $\quad$ Ideal EG Process \\
\hline
\end{tabular}

Figure 6. Asahi Kasei's new process: Closest to the ideal process.

On comparing Figure 6 with Figure 5, it is easy to understand that the new process is closest to the ideal process, because $\mathrm{CO}_{2}$ and bisphenol-A are supplied to the factory as raw materials and $\mathrm{PC}$ is withdrawn from the factory as a product. Assuming that the only one reaction is carried out at the factory, the horizontal reaction is basically same as the ideal PC production process as shown in Figure 5, although no water forms. We have made the closest ideal reaction possible with the aid of ethylene oxide (EO). The vertical reaction is also the ideal process for monoethylene glycol (MEG), because the reaction does not use water absolutely for producing MEG quantitatively.

Furthermore, any $\mathrm{CO}_{2}$ is available in the new process, but it is preferable to utilize the by-produced $\mathrm{CO}_{2}$ in the ethylene oxide (EO) production step by oxidation of ethylene, because the oxidation of ethylene with oxygen to EO is necessarily accompanied with the by-production of $\mathrm{CO}_{2}$ in about $15-20 \%$ yield, and it has been released into the atmosphere until now. The chemical reactivity of $\mathrm{CO}_{2}$ is very low, and thus difficult to be incorporated into the polycarbonate main chain. However, in the new process, the several novel methods have been developed to activate the $\mathrm{CO}_{2}$, in which the methods enable to proceed the desired reactions effectively and selectively, as a result, all used $\mathrm{CO}_{2}$ is successfully introduced into PC and monoethylene glycol (MEG) as the components consisting their main chains. That is, the $\mathrm{CO}_{2}$ is chemically divided into $\mathrm{CO}$ part and $\mathrm{O}$ part, and the $\mathrm{CO}$ part becomes $\mathrm{PC}$ component and the $\mathrm{O}$ part becomes MEG component.

Figure 7 shows the detail reactions 1 to 4 in the new process. In the first reaction, $\mathrm{CO}_{2}$ reacts with ethylene oxide (EO) to produce ethylene carbonate (EC). In the second reaction, EC reacts with $\mathrm{MeOH}$ to produce dimethyl carbonate (DMC) and ethylene glycol (EG). In the third reaction, $\mathrm{DMC}$ reacts with $\mathrm{PhOH}$ to produce diphenyl carbonate (DPC) and $\mathrm{MeOH}$. In the fourth
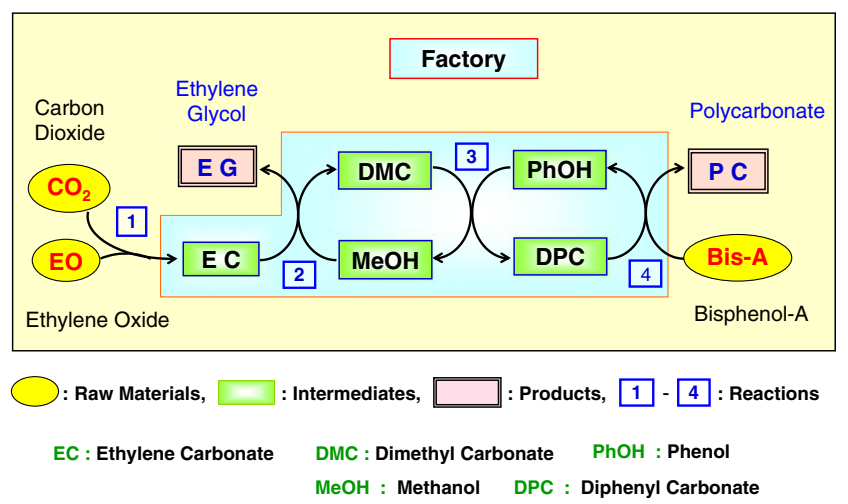

Figure 7. Asahi Kasei's non-phosgene PC process.

reaction, DPC reacts with bisphenol-A to produce $\mathrm{PC}$ and $\mathrm{PhOH}$.

Main characteristic features of Asahi Kasei's new process are as follows:

(1) The new process has no environmental drawbacks that are present in the phosgene process described above. The new process is phosgene free, $\mathrm{CH}_{2} \mathrm{Cl}_{2}$ free, $\mathrm{Cl}$ free, no-corrosive.

(2) $\mathrm{CO}_{2}$ as starting material is preferably the by-product in the production of ethylene oxide (EO), which has been mass-produced as a raw material of ethylene glycol (EG) for PET bottles, films, and fibers, etc.

(3) High yields and high selectivities are achieved in both the monomer production step and the polymer production step.

(4) All intermediate products, ethylene carbonate (EC), dimethyl carbonate (DMC), $\mathrm{MeOH}$, diphenyl carbonate (DPC), and $\mathrm{PhOH}$ are completely used up or recycled as raw material for the next or preceding reaction.

(5) There are no wastes, and no waste water necessary for disposal treatment before discharging.

(6) Monoethylene glycol (MEG) can be produced quantitatively with energy-saving.

(7) The melt polymerization step uses a unique original reactor which utilizes only gravity of the earth without using mechanical agitation, although mechanical agitation is indispensable for the conventional twin-screw type reactors developed in the many other companies.

(8) Purification and separation steps for the PC are unnecessary. The molten PC obtained from the polymerization step is directly introduced to extruder and palletized, thus the energy for producing PC pellets being commercial product from the PC polymer is lower than the phosgene process. In contrast to this process, PC polymer is obtained in powder form in the phosgene process, and thus the powder form PC must be heated to melt and pelletized through extruder to obtain PC pellets. 
As described above, the new process is totally green, because not only the $\mathrm{CO}_{2}$ being released into the atmosphere is effectively utilized, but also no waste, no waste process water necessary for disposal, and materials- and energy-savings are all achieved.

\section{MONOMER PRODUCTION PROCESS}

In order to produce high-purity and high-performance polycarbonate (PC) by the non-phosgene processes, it is indispensable to use very high pure bisphenol-A and diphenyl carbonate (DPC). High-purity bisphenol-A is commercialized in large quantity and available for producing PC in industrial scale. However, DPC has not been commercialized for industrial scale production of PC. Only several hundreds tons of DPC containing Cl-compounds impurities has been produced for chemical reagent use by using the reaction of phosgene with phenol, but the price is several times that of PC itself.

In order to prepare DPC without using phosgene, several attempts have been proposed. Among them, the direct synthesis of DPC by oxidative carbonylation reaction of phenol with $\mathrm{CO}$ and oxygen may have some potential for commercialization. Since GE patents have disclosed the possibilities of this reaction using Pd compounds as main catalyst and co-catalyst performing red-ox action in the presence of complex amines in $1978,{ }^{12}$ more than 100 patens and reports have been published until now. Various catalyst systems or the means for proceeding the reaction have been proposed to improve the turn over number of Pd or the yield of DPC. ${ }^{16}$

We have discovered the simplest catalyst system enable to produce clear DPC with high selectivity in a moderate yield. ${ }^{17}$ The catalyst system consists of only Pd and iodide components such as NaI. This simple catalyst system does not need to use both any cocatalyst containing other transition metals and any amines. When Pd metal such as Pd black and NaI are used as the catalyst system, the clear $\mathrm{PhOH}$ solution containing the reaction mixture is obtained after filtering off the Pd black. And pure DPC is obtained after distillation of the reaction mixture.

However, the technology of the direct synthesis of DPC by oxidative carbonylation of PhOH is not possible at a level to permit commercialization.

Thus, it is very difficult to produce DPC industrially except by reaction of phosgene with phenol. Nonphosgene and high-purity DPC production technology should thus be developed for industrialization. Especially, the impurities, such as chloride compounds, alkali and alkaline earth metal compounds, must not be contained in DPC, because even very small amount of them as less than $10 \mathrm{ppb}$, they exert bad effect on the polymerization step and properties of PC.

We have succeeded in development and industrialization the new process for producing very high-purity DPC containing none of these impurities in high yield with high selectivity from $\mathrm{CO}_{2}$, ethylene oxide (EO) and phenol. This new process for DPC production consists of three steps, ethylene carbonate (EC) production step, dimethyl carbonate (DMC) and monoethylene glycol (MEG) production step, and DPC production step.

\section{Ethylene Carbonate (EC) Production Step}

There are a lot of EOG (ethylene oxide and ethylene glycol) plants, and EO is produced annually at about 16 million tons all over the world. In all EO plants, EO is produced by oxidation of ethylene with oxygen. The yield of EO does not exceed about 80$85 \%$ by no means, because this oxidation reaction using oxygen at high temperature in the presence of $\mathrm{Ag}$ catalyst necessarily by-produces $\mathrm{CO}_{2}$ in about 15-20\% yield. ${ }^{18}$ (Scheme 2). Almost all $\mathrm{CO}_{2}$ by-produced at EOG plants is usually released into the atmosphere.

However, in the Asahi Kasei's new process, the $\mathrm{CO}_{2}$ by-produced in the EO plant is effectively utilized as raw material, and $\mathrm{EC}$ is produced almost quantitatively by reaction of $\mathrm{CO}_{2}$ with $\mathrm{EO}$ in the liquid phase or super critical phase (Scheme 3).

Reaction (c) proceeds smoothly using a catalyst, such as alkali or alkaline earth metal halides, amines, quaternary ammonium or phosphonium salts, guanidine, Lewis acid-amine complex compounds and anion-exchange resins containing quaternary ammonium salts to give EC continuously in a high yield. ${ }^{19}$ The commercial production of EC is performed by this method, but several process improvements for the new EC plant have been made to produce highquality EC quantitatively. For DPC production, the new EC plant has been constructed near EO plant and has been smoothly operating.

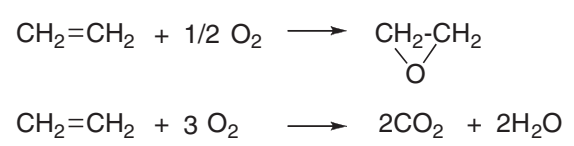

Scheme 2. Reaction (a): EO formation, and reaction (b): $\mathrm{CO}_{2}$ by-production.

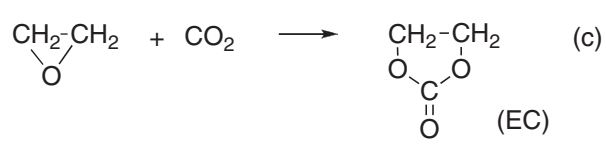

Scheme 3. Reaction (c): EC formation. 


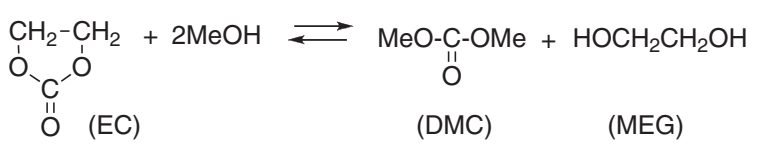

(d)

Scheme 4. Reaction (d): DMC and MEG formation.

\section{Dimethyl Carbonate (DMC) and Monoethylene Gly- col (MEG) Production Step}

Reaction (d) of ethylene carbonate (EC) with $\mathrm{MeOH}$ to produce DMC and Ethylene Glycol (EG) is an equilibrium reaction as shown in Scheme 4. The equilibrium constant is very low $(K=$ about 0.07), and thus high conversion of EC and completion of reaction without using extremely excess of $\mathrm{MeOH}$ are usually not possible.

Until our development, three methods had been proposed to progress this reaction. The first one is a complete batch method in which the reaction is conducted in an autoclave at the temperature of higher than the boiling point of $\mathrm{MeOH}$ in the presence of a catalyst under pressure. ${ }^{20}$ The second one is a batch reaction method using a batch reactor fitted with a distillation column on the reactor. In this method, reaction occurs only in the reactor existing a catalyst, while the distillation column works for separation of azeotropic mixture of $\mathrm{DMC} / \mathrm{MeOH}$ and $\mathrm{MeOH}$ vaporized and works for returning the $\mathrm{MeOH}$ to the reactor. ${ }^{21}$ However, it is very difficult to obtain DMC and MEG in high yields by this method, because the MEG produced easily reacts with the unreacted EC in the reactor to give higher molecular weight byproducts, such as diethylene glycol carbonate, triethylene glycol carabonate etc. Although the selectivity of MEG can be improved some degree by use of a large excess of $\mathrm{MeOH}$, the degree of the improvement is not enough.

The third one is a continuous method using a tubular reactor. ${ }^{22}$ However, this method does not achieve high conversion of EC, because of the low equilibrium constant, even with excess $\mathrm{MeOH}$ such as $\mathrm{MeOH} /$ $\mathrm{EC}=4 / 1$ (molar ratio). The conversion of $\mathrm{EC}$ is only about $25 \%$ at $130^{\circ} \mathrm{C}$.

Thus, these three methods proposed until now have several drawbacks such as the reaction time is long, a large excess of $\mathrm{MeOH}$ must be used to lower production of high boiling point by-products, high yields of DMC and MEG with high selectivity are not possible and complete recovery of the unreacted EC in the presence of EG is difficult. These methods are thus not suited for commercial scale.

In the above-described situation, we have made extensive and intensive studies to develop a process free from the drawbacks of these methods. ${ }^{23}$ As a result, we have developed the process enables to produce
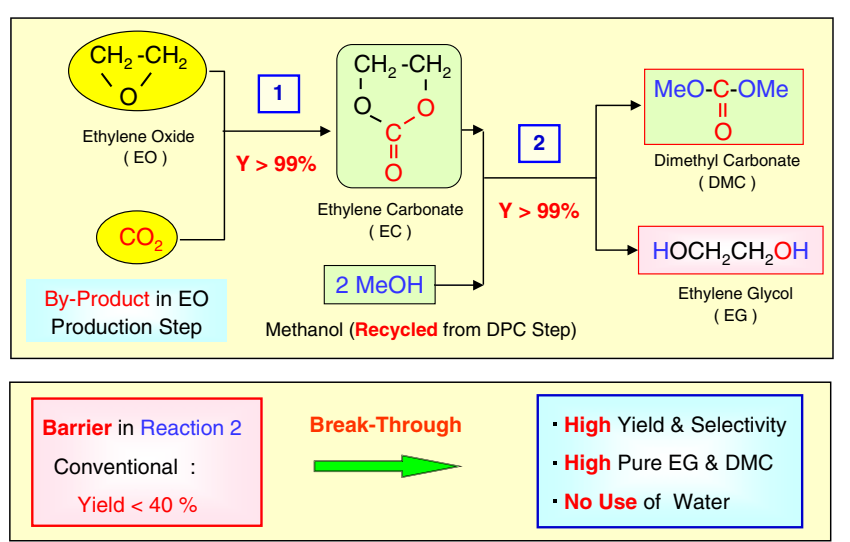

Figure 8. Break-through (1) in the monomer production step. (EC, DMC-EG steps)

$2 \mathrm{MeOH}+\mathrm{CO}+1 / 2 \mathrm{O}_{2} \longrightarrow \mathrm{MeO}-\mathrm{C}-\mathrm{OMe}+\mathrm{H}_{2} \mathrm{O}+\left(\mathrm{CO}_{2}\right)$

Scheme 5. Reaction (e): Oxidative carbonylation of $\mathrm{MeOH}$.

high-purity DMC and high-purity MEG from EC and methanol $(\mathrm{MeOH})$ in quantitative yields respectively, despite the reaction restricted by equilibrium. This is one of the excellent break-through in the monomer process (see Figure 8)

In the new method, the inherent characteristics of the reaction of $\mathrm{EC}$ with $\mathrm{MeOH}$, for example, the equilibrium reaction, high reactivity of EC with the hydroxy compounds, and azeotrope formation of the raw materials and the products etc., have been fully considered, and the facilities and the operation conditions have been designed to achieve almost complete conversion with avoiding the side reactions.

Thus, in the second step of monomer production process, very high-purity DMC containing none of chlorides impurities are produced in contrast to other conventional DMC processes.

For the use of PC production, another process for production of DMC has been already industrialized by GE group, in which oxidative carbonylation reaction (e) of $\mathrm{MeOH}$ with $\mathrm{CO}$ and oxygen is conducted in the presence of a large amount of $\mathrm{CuCl}-\mathrm{CuCl}_{2}$ slurry catalyst developed by Enichem Synthesis S.p.A. ${ }^{24}$ (Scheme 5)

However, it is said that this oxidative carbonylation process has several shortcomings and, has to be more improved to establish as a greener process. ${ }^{25}$

(1) The selectivity of DMC based on CO is low as 65$70 \%$, and significant amounts of $\mathrm{CO}_{2}$ (about $30 \%$ ) byproduction is unavoidable.

(2) The reaction system is highly corrosive and erosive, because it contains $\mathrm{HCl}$, high concentrated $\mathrm{CuCl}-\mathrm{CuCl}_{2}$ slurry and the water produced. It has 
GSC in Practice: Novel Non-Phosgene PC Production Process from $\mathrm{CO}_{2}$

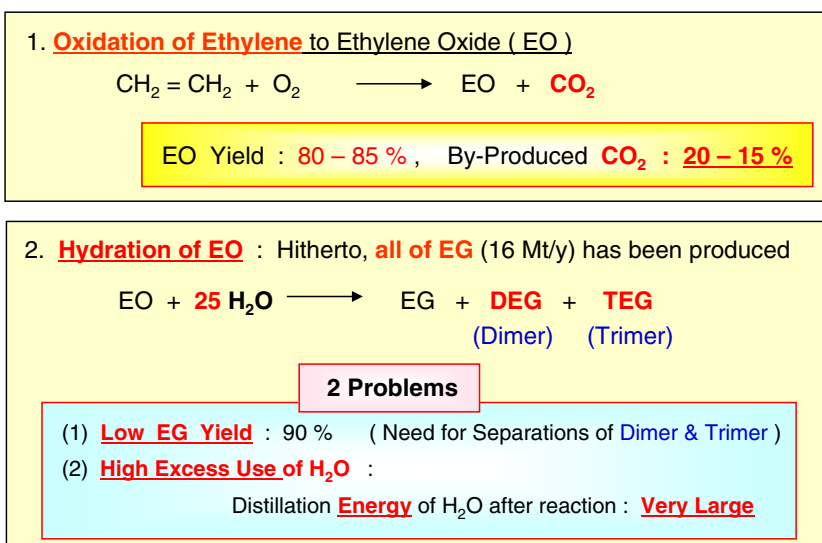

Figure 9. Problems in the conventional EOG process.

been easily supposed that the DMC plant has faced the severe troubles of corrosion, because the patents applied after operation of the DMC plant have describe about corrosion of the facilities. ${ }^{26}$

(3) The DMC contains chlorides impurities (methyl chloroformate, $\mathrm{HCl}$ etc.) derived from the catalyst system which are difficult to remove. It is well known that very small amounts $(<0.1 \mathrm{ppm})$ of chlorides impurities exert bad effects not only on the polymerization reaction but also on the performance of polycarbonate produced. In order to obtain high-purity DMC, the precise separation steps are necessary. However, these steps would lead to lower the yield of DMC and to increase energy consumption.

(4) The water, another product, must be separated from the reaction mixture and treated before discharge.

DMC production step in the Asahi Kasei's new process has none of these shortcomings, therefore, it is greener than the conventional process.

Furthermore, in the second step, an attention must be paid to the EG production. High-purity MEG can be produced in high yield. All of ethylene glycol (EG) in the world (15 million tons/year) has been produced by reaction of EO with water.

However, the conventional EOG processes have serious problems as shown in Figure 9.

At first, EO yield is low as $80-85 \%$ already described in the ethylene carbonate (EC) production step. Secondly, EG production process consisting of EO hydration has at least two big problems to be solved as follows.

(1) The yield of MEG is low, and oligomers such as diethylene glycol (DEG), triethylene glycol (TEG) are necessarily by-produced in more than $10 \%$ yield. Much energy is required to separate these by-products by distillation.

(2) In order to produce MEG with about $90 \%$ selectivity, a very large excess of $\mathrm{H}_{2} \mathrm{O}$ as much as 22-25

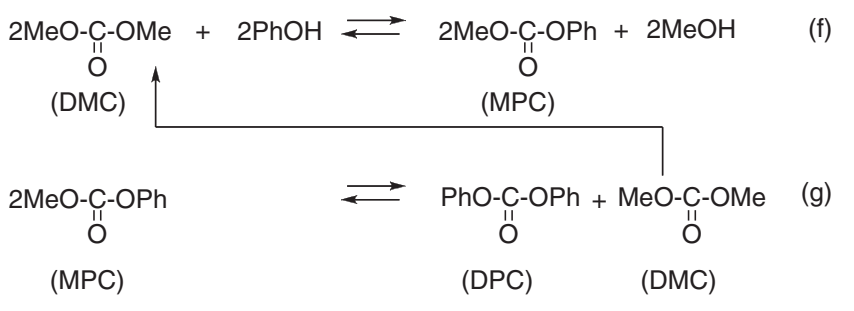

Scheme 6. Reaction (f): Transesterification reaction of DMC with $\mathrm{PhOH}$, and Reaction (g): Disproportionation reaction of MPC.

times in mol to EO must be used. This means that the very large amounts of $\mathrm{H}_{2} \mathrm{O}$ remaining in the reaction mixture must be separated by distillation from the products, so a very large quantity of energy must be consumed for the distillation.

In contrast with the conventional EG process, the second step of the Asahi Kasei's new process can produce high-purity MEG in a high yield with high selectively (more than $99 \%$, respectively) using $\mathrm{MeOH}$ instead of $\mathrm{H}_{2} \mathrm{O}$, wherein the molar ratio of $\mathrm{MeOH}$ to $\mathrm{EC}$ is not so large. The new process thus achieves energysaving in a high level, because there are none of $\mathrm{H}_{2} \mathrm{O}$ and by-products such as DEG to be distilled off, and the amount of $\mathrm{MeOH}$ to be distilled off after the reaction is not so much, and further both values of the latent heat for vaporization and the specific heat of $\mathrm{MeOH}$ are only about half those of $\mathrm{H}_{2} \mathrm{O}$.

\section{Diphenyl Carbonate (DPC) Production Step}

In the third step of the Asahi Kasei's monomer process, DPC is produced by using the combination of two reactions from dimethyl carbonate (DMC) and $\mathrm{PhOH}$. Main reactions occurring in the process are as follows. At first, methylphenyl carbonate (MPC) is produced by transesterification reaction of DMC with $\mathrm{PhOH}$ (reaction (f)), then 2 moles MPC are disproportionated to DPC and DMC by self-transesterification reaction (reaction $(\mathrm{g})$ ). The DMC produced in the reaction $(\mathrm{g})$ is recycled to the first transesterification reaction (f), and the $\mathrm{MeOH}$ produced in the reaction is recycled to the DMC and MEG production step (Scheme 6).

Both of these reactions are equilibrium reactions having low equilibrium constants respectively. Especially, the reaction (f) has an extremely small equilibrium constant $\left(\mathrm{K}=10^{-3}-10^{-4}\right)$, and is quite slow. And also the side reactions such as etherification and decarboxylation easily occur to give anisol and $\mathrm{CO}_{2} \cdot{ }^{27}$ (Scheme 7). Commercialization using these reactions is thus attended with difficult problems.

Our innovative process produces very high-purity DPC, which is indispensable for high performance polycarbonate, in a high production rate with high se- 


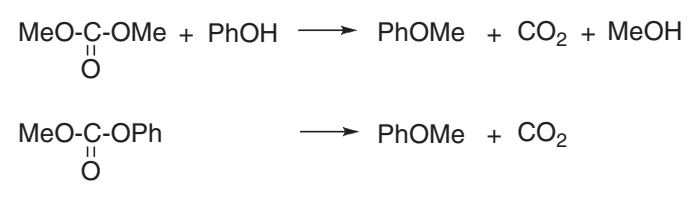

Scheme 7. Anisol and $\mathrm{CO}_{2}$ formation: Etherification of DMC with $\mathrm{PhOH}$, and Decarboxylation of MPC.

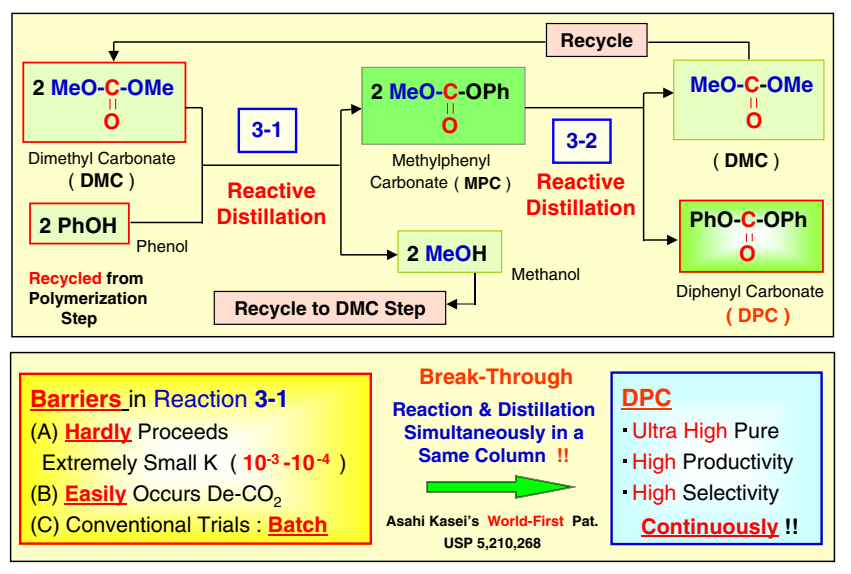

Figure 10. Break-through (2) in the monomer production step. (DPC step)

lectivity (>99\%). The two reactions (f) and (g) are conducted using two continuous multi-stage distillation columns connected to each other. The reaction and products separation by distillation are carried out simultaneously in the each column. The technology that the reaction and the products separation by distillation are carried out simultaneously in the same distillation column is called a reactive distillation. This reactive distillation technology for producing DPC was firstly disclosed in the world by our patents. ${ }^{28}$ This is the most important break-through in the monomer production process (see Figure 10)

Before the disclosure of our patents, all efforts for producing DPC had been focusing on development of the catalyst to enhance reaction rate of DMC with $\mathrm{PhOH}$ and on prevention of taking away of DMC from the reaction system by azeotrope with produced $\mathrm{MeOH}$. In these researches and developments, the reactions were carried out batch-wisely in the reactor (tank or flask) fitted with distillation column on the reactor, in which the reaction occurred only in the reactor existing the catalyst and no reaction occurred in the column portion. ${ }^{29}$ At that time, there was only one method for producing DPC continuously using a tube reactor packed with molecular sieves to absorb produced $\mathrm{MeOH},{ }^{30}$ and thus differs completely from the reactive distillation method. Subsequent to the disclosure of our patents, many patent applications for DPC production using the reactive distillation technology have been made. ${ }^{31}$
In this step, at least two reactive distillation columns connected to each other must be used, therefore, it is more complicated and difficult to produce highpurity DPC smoothly. We had to construct the pilot scale facilities in several times. The pilot facilities were capable for reaction and distillations under pressure in the first column and under reduced pressure in the second column, and we had to practice the long term operations under different conditions in many, many times, because it is very difficult to make the steady states to operate the combined two or more distillation columns with conducting many reactions, many distillations and many recycling of the materials. Such hard and long term endeavors lead to the establishment of this technology. As a result, we have able to obtain the ultra high pure DPC with high productivity and high selectivity continuously at industrial scale. Concerning about this step, we have made a lot of patent applications. ${ }^{32}$

\section{POLYCARBONATE PRODUCTION PROCESS}

When we try to produce the PC in a large scale by transesterification reaction of bisphenol-A (Bis-A) with DPC accompanying with removal of the $\mathrm{PhOH}$ by-produced from the reaction mixture under high vacuum, we face to very difficult problem. This problem is particularly troublesome, because it is based on the essential feature existing in the polycondensation reaction of PC itself. In order to progress the polymerization, it is necessary to remove the $\mathrm{PhOH}$ produced by the equilibrium reaction effectively from the reaction mixture through the surface of the polymer.

However, in the case of PC, there is great increase in melt viscosity with progressing of the polymerization and the surface renewal of the polymer by mechanical stirring for removing $\mathrm{PhOH}$ becomes very difficult before reaching the required molecular weight. Thus, polymerization hardly progresses. In order to lower the melt viscosity and to progress the polymerization, it is necessary to make the reaction conditions more severely, that is, the higher reaction temperature than about $300^{\circ} \mathrm{C}$ under high vacuum less than about $133 \mathrm{~Pa}$ for a fairly long time. However, these severe reaction conditions are easy to give fatal damages to the PC produced, such as discoloration and deterioration of the physical properties. Thus, the difficult problems in the melt polymerization for PC without giving fatal damages have been remaining for long time. In this respect, the polycondensation reaction of $\mathrm{PC}$ is essentially different from the other condensation polymers, such as polyethylene terephthalate (PET) and polyamides (Nylons). One of the reasons why none of new comers could enter the commercial production of PC for long time until now is 


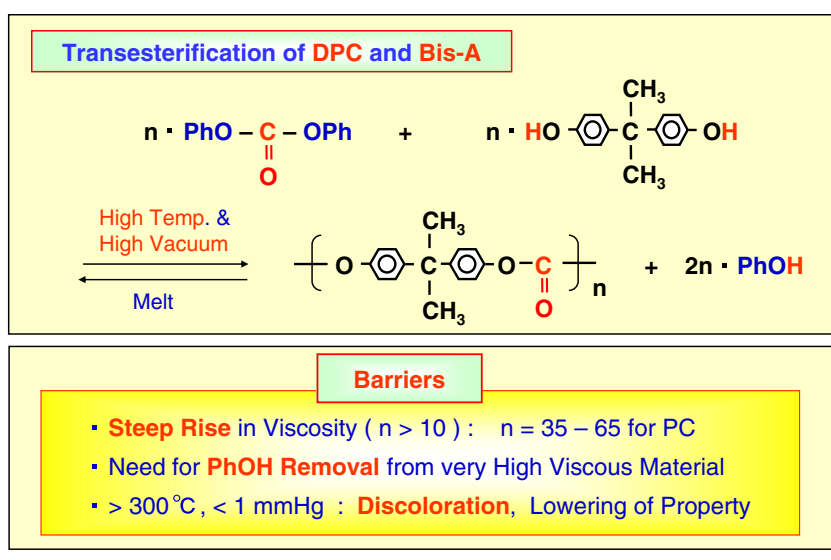

Figure 11. Barriers in the melt polymerization of PC.

because of the presence of these barriers difficult to be solved in the polymerization step. (See Figure 11)

In the pre-polymerization step, the PC pre-polymer having the polymerization degree $n=$ about 10 from the molten mixture of Bis-A and DPC can be obtain without such difficulty owing to the relatively low melt viscosity. However, the polymerization degree becomes more than about 10 , the melt behavior rapidly changes from the previous one and a drastic increase in melt viscosity occurs. The required polymerization degree (n) of PC as an engineering plastic is about 35-65, so post-polymerization step is necessary. For the post-polymerization step, we have developed successfully two different processes capable of industrialization to overcome these barriers based on the extremely high melt viscosity of PC. One is the solid-state polymerization process, and the other is the melt polymerization using unique reactor without mechanical stirring. The melt polymerization process using the latter reactor has been industrialized.

\section{Solid-state Polymerization Process}

This post-polymerization process of PC is based on our new concept of solid-state polymerization for amorphous polymer, and it is published in "Green Chemistry, Designing Chemistry for the Environment" (ACS Symposium Series 626, Chapter 2). ${ }^{33}$ Different from amorphous polymer such as PC, crystalline polymers such as PET and Nylon are known that the solid-state polymerization of the pellets having sufficient molecular weight for general purpose is carried out to obtain higher molecular weight polymer for special use such as tire cord. ${ }^{34}$ However, none of trials to produce PC resins by solid-state polymerization appeared prior to our disclosure. The reasons is possibly that $\mathrm{PC}$ is an amorphous polymer having $T_{\mathrm{g}}=154{ }^{\circ} \mathrm{C}$ and even if the molecular weight is enough for an engineering plastic, the molten state occurs before reaching the temperature necessary for polymerization $\left(>200^{\circ} \mathrm{C}\right)$. Therefore, it is practical sense that solid-state polymerization of the PC prepolymer having lower $T_{\mathrm{g}}$ than that of $\mathrm{PC}$ polymer as the post-polymerization has been thought to be impossible.

We have overcome such practical sense by developing the following technologies.

(1) The technology for turning the amorphous PC prepolymer to a crystallized porous pre-polymer having high melting point sufficient to maintain the solidstate at the polymerization temperature:

The technology is based on the finding that amorphous PC pre-polymer having polymerization degree $n=$ about $10-20$ easily crystallizes on contact with a solvent such as acetone to give a porous crystalline powdery pre-polymer having melting point of 225$230^{\circ} \mathrm{C}$ and surface area exceeding about $2 \mathrm{~m}^{2} / \mathrm{g}$ (see Figure 12). At first, this fact was found when acetone

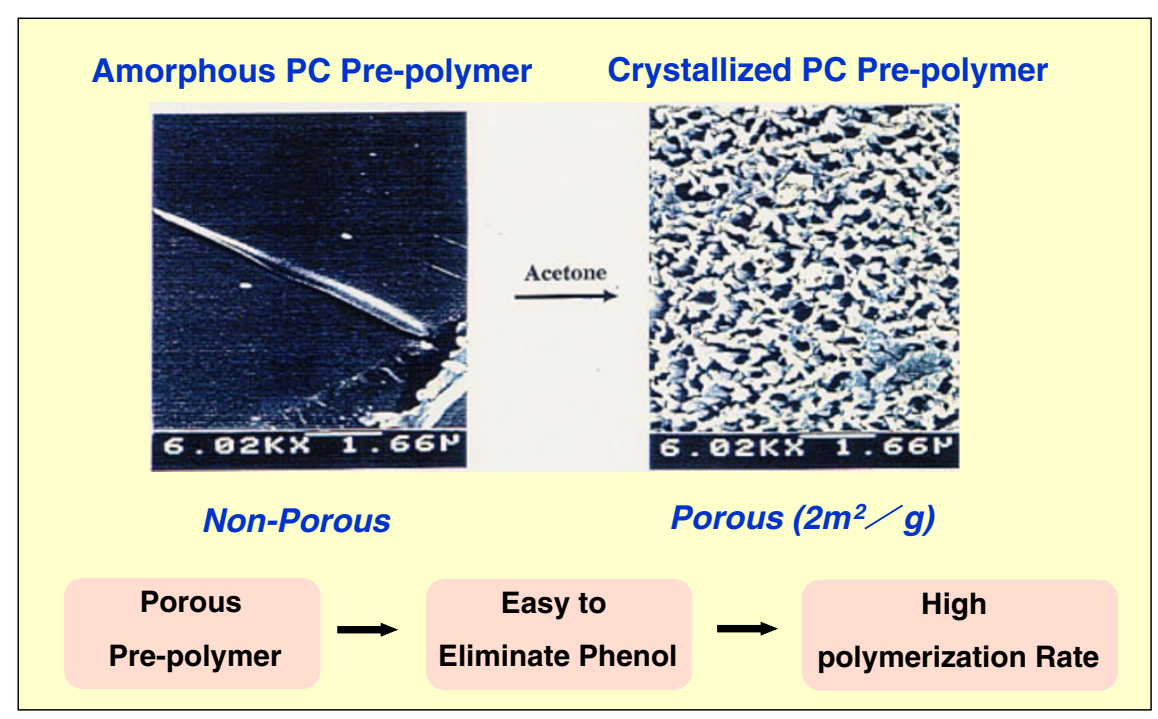

Figure 12. Crystallization of amorphous PC pre-polymer. 
was poured into the glass flask containing the amorphous PC pre-polymer fixed to the surface of the glass to remove off the pre-polymer from the flask. When the surface of the pre-polymer immersed in acetone was scrubbed with a spatula, a small amount of white powder material was obtained and found to be a crystallized porous PC pre-polymer. In the bench stage development, this crystallization step was improved as that many strands of molten amorphous PC pre-polymer were immersed into the acetone with stirring to produce white crystallized pre-polymer powder. In the pilot facilities, further improvements for reducing the amount of the crystallization solvent had been done. Instead of immersing amorphous pre-polymer, the new crystallization step has been developed, in which the small particles of the amorphous pre-polymer were pulverized in the presence of small amount of the solvent to cause crystallization. These small particles of the amorphous pre-polymer can be also crystallized by remaining in the atmosphere of the crystallization solvent vapor or only with heat application without solvent vapor.

(2) The technology conducting solid-state polymerization without adhesion of crystallized pre-polymer: In the laboratory scale, the porous crystallized PC prepolymer easily polymerizes at relatively low temperatures as $210-220^{\circ} \mathrm{C}$ with effective removal of $\mathrm{PhOH}$ under reduced pressure and/or under blowing of inert gas $\left(\mathrm{N}_{2}, \mathrm{CO}_{2}\right.$, Lower hydrocarbon, etc.). However, when we try to make scale-up the solid-state polymerization of PC, we faced to the troublesome problems that the powdery crystallized PC pre-polymer easily adhesive with each other. This troublesome problem has been solved by the two different kinds of approaches. One is based on the fact that the crystallized pre-polymer having small pellet shape can extremely reduced the adhesion. And the continuous process for preparing the small pellet shape crystallized prepolymer has been developed. The other is based on the development of the solid-state polymerization facilities for avoiding adhesion. Various solid-state polymerization facilities at bench and pilot stages have been set up capable industrialization could thus be developed (see Figure 13).

In 1987, we made the world's first patent application for the solid-state polymerization of PC with removal of $\mathrm{PhOH}$, and this patent application was disclosed in 1989, and has been patented in the many countries (U.S. Patent. in 1990, Eur. Pat. in 1994, Jap. Pat. in 1995, etc.). ${ }^{35}$

In our solid-state polymerization, the obtained PC has excellent properties without discoloration and deterioration because the polymerization temperature is lower about $70-80^{\circ} \mathrm{C}$ than the conventional melt polymerization being necessary more than $300^{\circ} \mathrm{C}$.

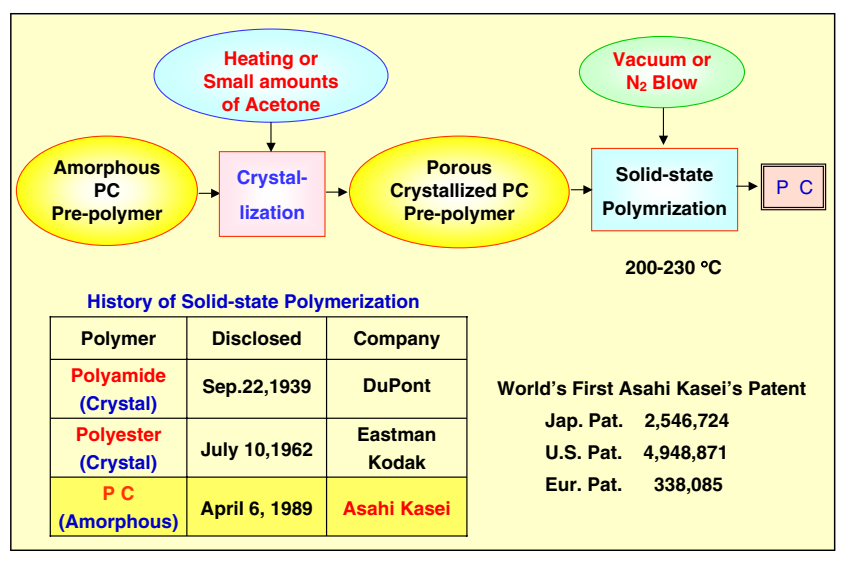

Figure 13. Break-through (3) in the polymer production step: Solid-state polymerization of PC.

In order to explain the principle of the solid-state polymerization of PC from bisphenol-A and DPC, one example of the laboratory scale experiments is shown as follows.

$68.4 \mathrm{~g}$ of bisphenol-A and $77.0 \mathrm{~g}$ of DPC produced by the reactive distillation method described above were put into a $500 \mathrm{~mL}$ three-necked flask provided with a stirrer, a gas inlet and a gas suction port. De-aeration by applying vacuum and introduction of dry nitrogen were performed five to six times. Then, the flask was immersed in an oil bath kept at from 180 to $190^{\circ} \mathrm{C}$, thereby melting the content of the flask. Again, de-aeration by applying vacuum and introduction of dry nitrogen were performed. Thereafter, the temperature of the oil bath was elevated up to $230^{\circ} \mathrm{C}$, and dry nitrogen was introduced into the flask at a rate of $25 \mathrm{l} / \mathrm{h}$ (volume at normal temperature and pressure) while stirring so as to distill off formed phenol. About 50 min later, the reaction system was evacuated, and the reaction mixture was stirred at from 260 to $660 \mathrm{~Pa}$ for about $15 \mathrm{~min}$, thereby distilling off phenol and DPC. As a result, there was obtained $7 \mathrm{~g}$ of a colorless, transparent pre-polymer having $M_{\mathrm{w}}=6,200$. The pre-polymer had terminal-OCOOPh groups and terminal-OH groups in amounts of 72 mole $\%$ and 28 mole $\%$, respectively, based on the total number of moles of all the terminal groups of the pre-polymer. The pre-polymer was taken out of the flask and pulverized. The resultant powdery pre-polymer was immersed in $250 \mathrm{~mL}$ of acetone, thereby effecting crystallization of the pre-polymer. The crystallization of the pre-polymer occurred immediately after the immersion. 30 Min after the immersion, sufficient crystallinity was obtained, but immersion was further continued for $1 \mathrm{~h}$. The resultant white powdery crystallized pre-polymer was filtered off and dried. From the powder X-ray diffraction patterns, it has been found that the crystallized pre-polymer had a crystal- 
linity of about $30 \%$. With respect to the ratio of each of the terminal groups, there was substantially no change between the pre-polymer before the crystallization, i.e., amorphous pre-polymer, and that after crystallization, i.e., crystallized pre-polymer.

The powdery crystallized pre-polymer, was put into the same type flask as that used in the pre-polymer preparation. While introducing a little amount of dry nitrogen into the flask which was under 260 to $660 \mathrm{~Pa}$, the flask was put in a oil bath kept at $190^{\circ} \mathrm{C}$. While stirring the content of the flask, the temperature of the oil bath was elevated at a rate of $5^{\circ} \mathrm{C} / \mathrm{h}$. After the temperature of the oil bath reached $220^{\circ} \mathrm{C}$, stirring of the content of the flask was continued at this temperature for $8 \mathrm{~h}$ under a reduced pressure of 260 to $660 \mathrm{~Pa}$ while introducing a little amount of dry nitrogen, thereby effecting solid-state polymerization. As a result, there was obtained a white powdery crystallized PC having $M_{\mathrm{w}}=28,000\left(M_{\mathrm{w}} / M_{\mathrm{n}}=2.4\right)$. The thus obtained crystallized PC had a hydroxyl terminal group content of $0.001 \%$ by weight, based on the weight of the polymer. In contrast, with respect to commercially available PCs, the content of terminal hydroxyl groups is in the range of from about 0.01 to $0.05 \%$ by weight.

Test pieces were obtained by subjecting the white crystallized polycarbonate to customary injection molding. The testing pieces were colorless, transparent and tough. The test pieces were subjected to testing for boiling water resistance by putting in an autoclave containing water and heating at $120^{\circ} \mathrm{C}$ for $50 \mathrm{~h}$. As a result, although the $M_{\mathrm{w}}$ had been slightly reduced to 25,000 , no occurrence of crazing or discoloration was observed.

We had constructed three types (batch, semi-continuous and continuous) of the pilot scale facilities for producing PC by the solid-state polymerization. The white crystallized PC produced by these pilot facilities had been turned to the clear transparent amorphous PC pellets by means of melt extrusion and pelletization. These PC pellets produced by the pilot facilities had been evaluated by three PC producing companies and several molders from the late 1980s to the early 1990s. Their evaluations were all sufficient to satisfy us that Asahi's PC by the solid-state polymerization had some excellent features compared with the conventional PC produced by the phosgene process, and the other properties were at least as same levels as the conventional PC. They had also described that the Asahi's PC could have sufficient properties to compete with the conventional PC on the market.

Solid-state polymerization of $\mathrm{PC}$ has no relation to the ultra high melt viscosity which makes extremely difficult the melt polymerization of PC, and can produce high performance PC. Furthermore, our solid- state polymerization process can easily produce the higher molecular weight PC than the commercial PC, which the higher molecular weight PC has excellent properties such as solvent resistance and abrasion resistant.

After disclosure of the Asahi Kasei's technologies of the solid-state polymerization of PC, a lot of works from universities and companies in this field has been published. ${ }^{36}$

As a pioneer of the solid-state polymerization of amorphous PC, we are very glad to see the expansion of this technical field.

\section{Melt Polymerization Process}

In order to obtain the PC having the molecular weight required for engineering plastic (about $n=$ 35-65), post-polymerization is inevitably necessary as described above. There have been a lot of trials to practice the post-polymerization in the melt state. However, all of them have used the horizontal reactors, which have been developed for the polymerization of polymer having ultra high viscosity. These reactors have self-cleaning type twin-screw for mechanical mixing and surface renewal of ultra high viscosity polymer. ${ }^{37}$ However, it is well known that these reactors have several problems as shown in Figure 14.

(1) It is liable to discoloration of PC:Air or small size contaminants are easy to leak into the reactor through the seals of rotary axes, because the operation is carried out at high temperature under high vacuum. These leaks damage the color tone and physical properties of PC.

(2) It is liable to deterioration of PC: In order to obtain the $\mathrm{PC}$ having desired molecular weight, the residence time of the polymer in the reactor must be long. Such residence under at high temperature $\left(>300^{\circ} \mathrm{C}\right)$ and hjgh shear force by mechanical agitation causes to deteriorate the physical properties of PC. Furthermore, dead-spaces are present in this type reactor, and the polymer staying in these dead-spaces at high temperature for long time inevitably discolors to yellow, brown or black. The contamination of the discolored polymer into the product is fatal for the transparent PC. (3) It is unable to produce all grades necessary for commercial products.: It is difficult to produce the PC grades having middle to high viscosity. The grades are important for injection and extrusion products. Thus, even the most effective stirring systems now available cannot produce all grades of PC for general purpose.

(4) It is not energy-saving type reactor.: It needs to use a high power motor for rotating the twin axes and consume much electric energy for mixing very high viscosity polymer. 


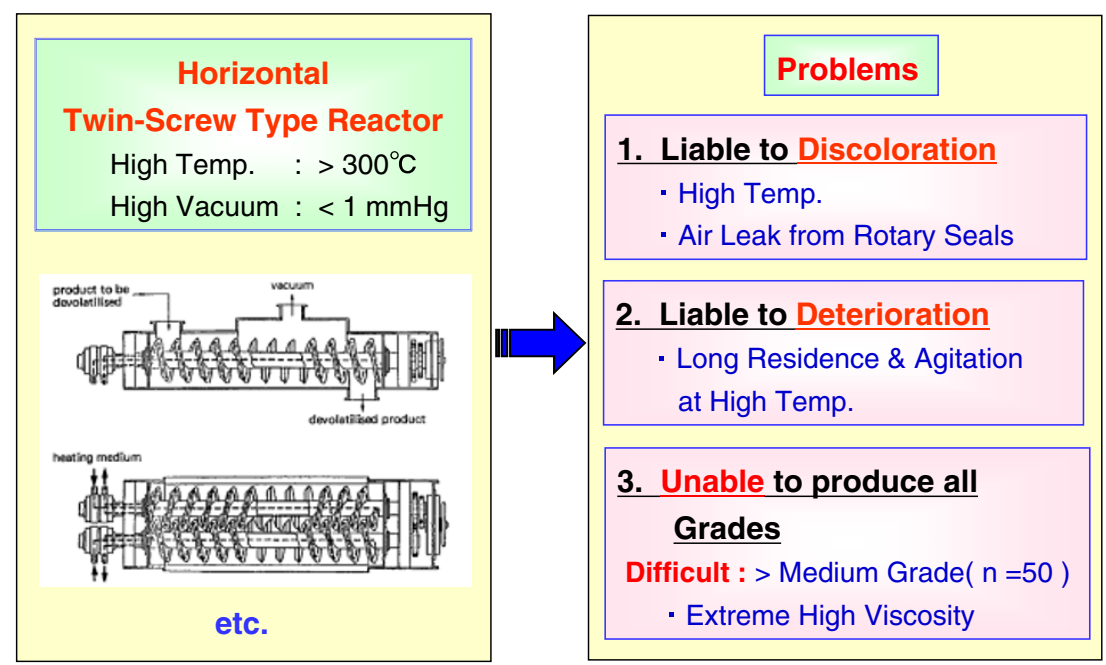

Figure 14. Conventional melt-state post-polymerization.

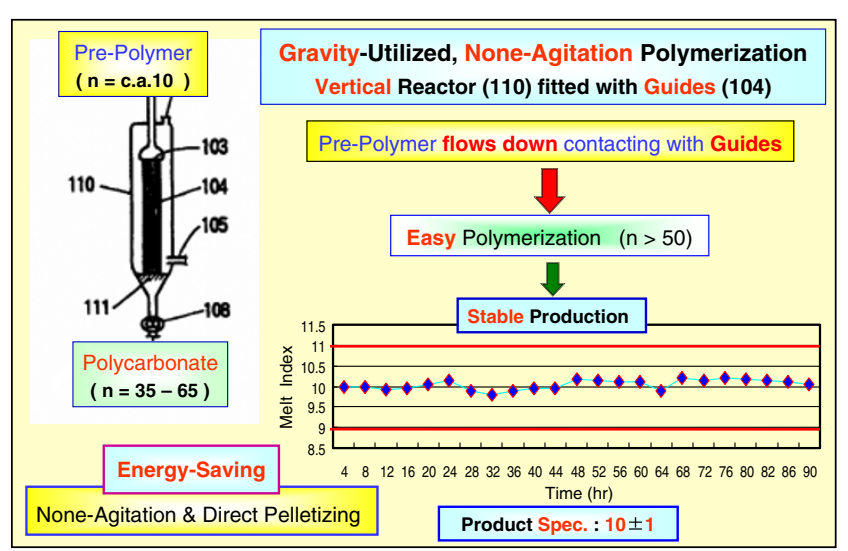

Figure 15. Break-through (4) in the polymer production step: Gravity-utilized, non-agitation polymerization (Melt-state postpolymerization).

We have tried to the melt polymerization from the new standpoint, and we have endeavored to solve the problems having these mechanical mixing type reactors for long times, we have succeeded in developing a new unique polymerization reactor. ${ }^{38}$ This innovative reactor utilizes only earth gravity without using any mechanical mixing system, so we would like to call this reactor "A Gravity-utilized, Non-agitation Polymerization Reactor." This is the world's first reactor for the polycondensation of PC (see Figure 15). This is the great break-through in the polymerization step.

The new reactor can smoothly conducts the postpolymerization reaction of $\mathrm{PC}$ during the pre-polymer flows down along the guides fitted vertically in the space of the reactor. In order to practice the surface renewal of the high viscosity material, it is usual that the mechanical agitation methods are tried and investigated what type of agitator is useful to achieve effective mixing.
It is a great surprise that in this reactor very effective surface renewal and agitation of the pre-polymer during flowing down along the guides is practiced and effective removal of the by-produced $\mathrm{PhOH}$ is attained, though there is no mechanical agitation. Consequently the polymerization reaction occurs easily and the desired molecular weight PC is obtained at the end of the guides.

The phenomena that when the highly viscous material is flowing down along the guide such as a wire the effective surface renewal and mixing of the high viscous material occurs, has been first established by the model experimental. The reactor model was made of transparent PVC pipe (inner diameter $=$ about $10 \mathrm{~cm}$, length $=5 \mathrm{~m}$ ) and a stainless steel wire (outer diameter $=$ about $2 \mathrm{~mm}$ ) was fitted at the center of the pipe fixed vertically. Transparent viscous starch syrup was continuously fed from the top of the wire and flowed down along the wire at room temperature. The starch syrup flowed down continuously as rod-like material surrounding the wire. In the steady state, a spot of red color dye was added to the starch syrup at the top of the reactor model. As flowing down the starch syrup, the spot of red color dye was spreading in the syrup and the pink colored homogeneous zone was observed. This means that the diffusion of the red spot into the rod-like material occurred by the effective mixing. Furthermore, more and more effective surface renewal and mixing were observed when the system was made under the reduced pressure, because a part of the water containing in the starch syrup was removed from the surface and the inside of the flowing material accompanying with vigorous foaming inside and surface of the starch syrup.

In order to explain the principle of the melt polymerization of PC using the Gravity-utilized, Nonagitation Polymerization Reactor, one example of 
the pilot scale experiments is shown as follows.

The polymerization was carried out using a vertical, cylindrical reactor which has an internal volume of $0.6 \mathrm{~m}^{3}$ and is equipped with thirty column-shaped guides made of stainless steel, each having a diameter of $1 \mathrm{~mm}$ and a length of $8 \mathrm{~m}$. The reactor is also equipped with distributing plate at upper position, through which pre-polymer fed to the reactor can be distributed to cylindrical guides so that the distributed prepolymer can be caused to uniformly fall along and in contact with the surface of each of cylindrical guides. Further, the reactor has an external jacket, and the inside is adapted to be heated by passing a heating medium through the jacket. The reactor has no agitating means for the pre-polymer. The pre-polymer having a $M_{\mathrm{n}}=6,200$, which had been prepared by reacting bisphenol-A with diphenyl carbonate produced by the method described above in a molar ratio of 1:1.05, was continuously fed to the polymerization reactor through the inlet fitted on the top part of the reactor at a flow rate of $18 \mathrm{~kg} / \mathrm{h}$, so that a polymerization reaction of pre-polymer was carried out under the conditions wherein the reaction temperature was $265^{\circ} \mathrm{C}$, and the reaction pressure was $67 \mathrm{~Pa}$, while continuously withdrawing a produced aromatic polycarbonate from outlet fitted under the bottom part of the reactor. Each of the polycarbonate products obtained $25 \mathrm{~h}$ and $50 \mathrm{~h}$ after the start of the polymerization reaction had a $M_{\mathrm{n}}=11,7000$. Both of the aromatic polycarbonate products were colorless, transparent and contained no impurities and thermal decomposition products.

Although we had found principle that the PC having high molecular weight could be obtained from the pre-polymer and the new polymerization reactor would be useful for the post-polymerization of PC, we had faced to the difficult problem, which had been to overcome for industrialization. That is, the remained problem was to establish the technology enable to produce the PC having the desired molecular weight necessary for the commercial products stably for long time such as more than several thousands hours.

A lot of factors that may make fluctuations of the molecular weight in this new polymerization method have been examined thoroughly. Those factors are for example as follows.

(1) Pre-polymer: molecular weight, kind of and amount of the polymerization catalyst, ratio of the terminal group $(-\mathrm{OH} /-\mathrm{OPh})$, etc.

(2) Guide, apparatus: type, length, shape, distance of the neighboring guides, etc.

(3) Polymerization conditions: feeding rate, temperature, pressure, etc.

(4) Uniformity of vertical changing: piston flow, resi- dence time, changing in the adhesive power, etc. (5) Horizontal uniformity: distributor, similar degree of the surface renewal, etc.

We have had to try innumerable cycles of planning based on the hypotheses, doing, seeing and thinking for stable production of $\mathrm{PC}$ in consideration of the above factors. Accordingly we have also had to construct several types of the pilot facilities suitable for the hypotheses and repeat again and again the operation and the improvements of the pilot plants. As a result, the stable production technology has been established. This stable production technology has been applied to the commercial plant, and the transition curve of the melt index (MI) in Figure 15 is an example showing the stable production of one of the grades of the commercial products.

The Gravity-utilized, Non-agitation Polymerization Reactor can easily produce the PC covering all of ranges of molecular weight of the commercial PCs from disk grade ( $n=$ about 35 ) to high viscosity grade for extrusion processing ( $n=$ about 65). Furthermore, this reactor can also produce the PC having a molecular weight higher than $n=$ about 65 .

This new reactor can produce the high-purity and high-performance PC having colorless and good transparency and good properties because the new reactor can produce the $\mathrm{PC}$ at less than $270^{\circ} \mathrm{C}$, which is lower more than $30^{\circ} \mathrm{C}$ the conventional melt polymerization using the twin-screw type reactors. There is no need for any type of agitators, which cause air leaks and small foreign contaminants.

The Gravity-utilized, Non-agitation Polymerization Reactor accords with the natural principle only utilizing the gravity of the earth, and it can also contribute to energy-saving. It is clear that the ultra high melt viscosity of PC makes melt polymerization of PC extremely difficult. To the contrary, the new reactor effectively utilizes the high viscosity of PC as the adhesive power to the guides maintaining the stable flowing down of the PC pre-polymer.

\section{EXCELLENT FEATURES OF PC PRODUCED BY THE ASAHI KASEI PROCESS}

The PCs produced by the new process have not only high-purity and high performance, and excellent in transparency but also other outstanding features, which can't be attained in the PCs produced by the conventional process.

\section{(1) Cl-Free}

The PCs produced by the Asahi Kasei Process contain none of chloride compounds because the process does not use any kind of chloride compounds in both the monomer production step and polymer production step. The PCs produced by the phosgene process 


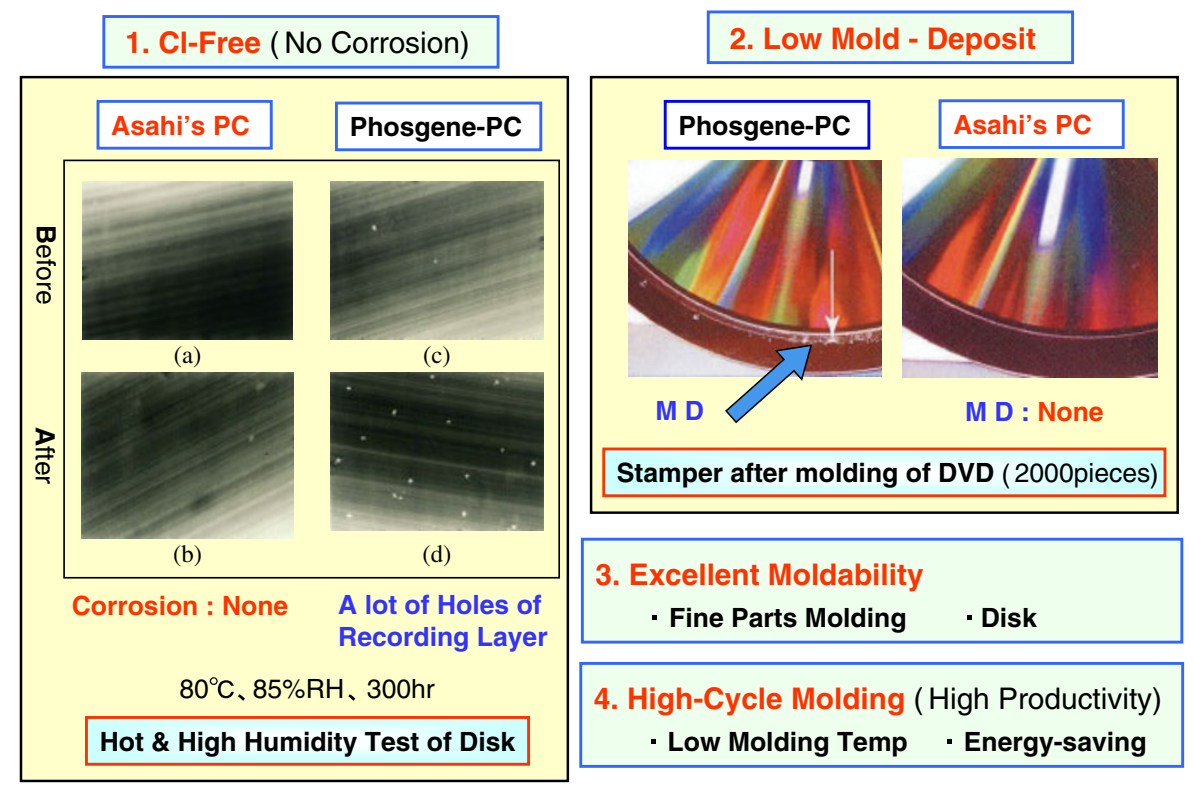

Figure 16. Excellent features of the PCs produced by the Asahi Kasei's process.

inevitably contain some chloride compounds such as $\mathrm{NaCl}$, chloroformates, chlorinated hydrocarbon $\left(\mathrm{CH}_{2} \mathrm{Cl}_{2}\right.$, chlorobenzene etc.). These chloride impurities cause to corrode the molding machines and the molds. Even the thoroughly purified disk grade PCs produced by phosgene process contains about several $10 \mathrm{ppm}$ to several $100 \mathrm{ppm}$ of the chloride compounds. The optical disk produced from these PCs may possibly corrode the recording layers during long time storage.

The microscopic photographs in Figure 16.1 show the results of the acceleration tests on optical disks at high temperature $\left(80^{\circ} \mathrm{C}\right)$ and high humidity $(85 \% \mathrm{RH})$ for $300 \mathrm{~h}$. None of holes of the recording layer can be observed in the Asahi's PC after testing (b) as is the case before testing (a). However, a lot of holes (white points) of the recording layer can be seen in the Phosgene-PC after testing (d).

Today, more than 500 thousands tons PC per year are used for optical disks in the world. It is clear that the PCs produced by the Asahi Kasei Process are suitable for the use of optical disks required for long life storages such as DVDs.

Recently, IC related industries have eagerly desired to get the materials containing none of chloride compounds. They have hated remarkably the presence of the chloride compounds in the materials contacting to the electronic parts even very small amount, because the chloride compounds cause the false working of the parts. As the PCs produced by the Asahi Kasei Process can completely satisfy the requirements of the IC related industries, the PCs produced by the Asahi Kasei process for the use of these field, for example, the carriers for the semi-conductor parts such as sili- cone wafers and for the precision instrument parts will increase.

(2) Low Mold Deposits

The PCs produced by the Asahi Kasei Process contain very small amount of the oligomers having $\mathrm{Mw}$ of less than 1000, therefore the amount of the mold deposits during the molding is quite small compared with the PCs produced by the conventional process. Accordingly, very long time molding operation can be attained without interruption of the molding for wiping or cleaning of the mold or the stamper. Prolonged molding operation is useful not only for the productivity improvement but also the man power-, material- and energy-savings. Thus, the molders have highly evaluated the PCs produced by the Asahi Kasei Process.

Figure 16.2 shows the photographs of the stampers after molding of DVD-RAM (2000 pieces) using PC produced by the phosgene process (Phosgene-PC) and PC produced by the Asahi Kasei Process (Asahi's PC) respectively (molding temperature: $380^{\circ} \mathrm{C}$, mold temperature: $100^{\circ} \mathrm{C}$ ). On the left-side stamper (Phosgene-PC), large amount of the mold deposit (MD) owing to oligomers is observed. However, on the rightside stamper (Asahi's PC), none of MD is observed.

(3) Excellent Moldability

The PCs produced by the Asahi Kasei Process have good flow characteristics compared with the Phosgene-PC under the molding conditions. Figure 17 shows the comparison of the spiral flow distances (SFD) between Asahi Kasei's-PC and Phosgene-PC having the same melt index $\left(\mathrm{MI}=14,300^{\circ} \mathrm{C}\right.$, $12 \mathrm{~kg}$ ) under the same molding conditions.

Figure 17 clearly shows that the SFDs of the Asahi 


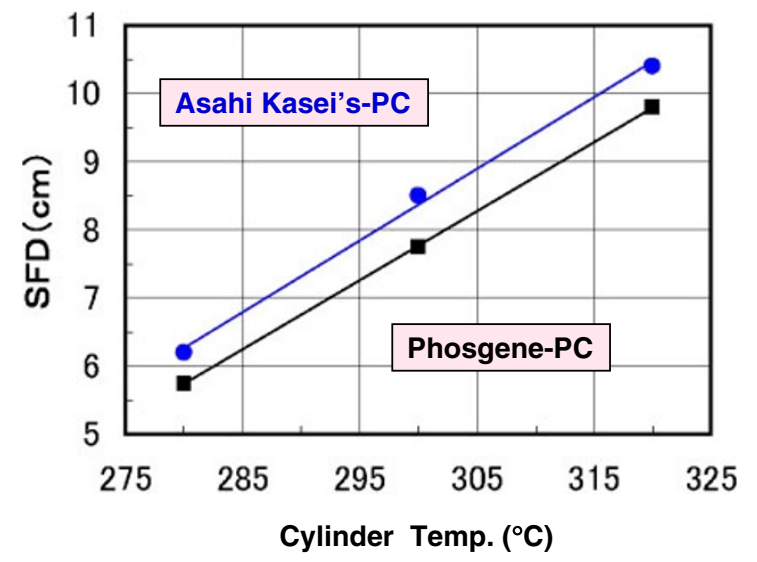

Figure 17. Comparison of the spiral flow distance (SFD) between Asahi Kasei's-PC and phosgene-PC $\left(\mathrm{MI}=14,300^{\circ} \mathrm{C}\right.$, $12 \mathrm{~kg})$.

Kasei's-PC are longer than those of the Phosgene-PC at any temperatures using usual injection molding. Therefore, the PCs produced by the Asahi Kasei Process are very suitable for the uses to produce the precision moldings. Especially, they are fit for the uses of the optical disks for information storages (DVDs) and the precision molding parts having fine and complex shapes. Because of their excellent flow characteristics, they can precisely transfer the ultra fine pits or grooves from the stampers for the optical disks, and can flow into the fine cavities of the precision molds.

(4) High-Cycle Molding

The PCs produced by the Asahi Kasei Process lowers the molding temperature by at least about $10^{\circ} \mathrm{C}$ and the mold temperature about $3-5^{\circ} \mathrm{C}$ compared to the PCs produced by the phosgene process. Therefore, the PCs produced by the Asahi Kasei Process make the high-cycle molding possible. The long time high-cycle molding (high productivity) is also possible owing to their features of the low MD.

\section{CONCLUSIONS AND FUTURE DEVELOPMENT}

Asahi Kasei's new non-phosgene PC process using $\mathrm{CO}_{2}$ as raw material satisfies almost all 12 Articles for Green Chemistry proposed by Dr. Anastas and Dr. Warner. ${ }^{39}$ That is, (1) no waste, and no waste water necessary for disposal treatment, (2) material-saving due to high yields and selectivity (>99\%), complete reuse by recycling of the all intermediates, (3) use of low toxic reactants: phosgene-free and $\mathrm{CH}_{2} \mathrm{Cl}_{2}$ free, (4) safer products: DPC alternates phosgene, (5) no use of sub-materials (solvent-free), (6) energy-saving due to high yields and selectivity; no use of $\mathrm{H}_{2} \mathrm{O}$ in EG production step, (7) $\mathrm{CO}_{2}$ as a raw material can be regenerated, (8) no chemical modification, (9) use of a small amount of catalysts and they are recycled in the monomer production steps, (10)

\section{Realization of Green Sustainable Chemistry}

1. Utilization of By-Product $\mathrm{CO}_{2}$ Emitted into Air

(1) Into PC Main-Chains

(2) $\mathrm{CO}_{2}$ Emission Reduction: $173 \mathrm{t} / \mathrm{PC} 1 \mathrm{kt}$

2. Safer Plant

(1) No-Use of Highly Toxic Phosgene

(2) No-Use of $\mathrm{CH}_{2} \mathrm{Cl}_{2}$

3. Environmentally Benign Process

(1) Wastes : None

(2) Waste Water to be treated: None

Figure 18. Contribution of Asahi Kasei's PC process to society.

good process control by using many instruments for analysis and control system, (11) phosgene-free, which means hard for a hazardous chemical accidents to occur. (12) There are no run-away reactions. All reactions are hard to occur chemical accidents.

Asahi Kasei's new non-phosgene process practicing Green and Sustainable Chemistry can contribute to society in several aspects. For example, utilization of $\mathrm{CO}_{2}$ emitted into air, safer plant and environmentally benign process as shown in Figure 18.

In addition to the above contribution in "Green and Sustainable Chemistry," the new process has also economic advantages to the conventional phosgene processes both in the plant construction $\operatorname{cost}^{40}$ and in the feedstock cost. ${ }^{41,42}$ Therefore, in order to satisfy the demand for increasing consumption of PC, the new plants using Asahi Kasei non-phosgene process are preferred to construct in the world. For this purpose, the Asahi Kasei Corp. group is willing to license the new technology to respond to the requirements without monopolizing, because there are a lot of requirements for licensing of the new process from about 20 companies involving the conventional PC producers.

Following the first commercial plant of ChimeiAsahi Corp. in Taiwan, on the basis of license contracts, the plants of the company in Russian, the two companies in Korean and the company in the Middle East are now under construction. Since the licensing to the other companies has been continued, the total capacities of PC production by the Asahi Kasei new non-phosgene process should become to share more than $25 \%$ in the world in the near future.

It is sure that the success in the industrialization of the new Asahi Kasei non-phosgene PC process in Chimei-Asahi corp. should accelerate the process changing of the PC production from the phosgene process to the non-phosgene process. Among them it is a good possibility that the Asahi Kasei's process 
should become a global standard process for the production of PC in the future. Furthermore, it is also a good possibility that the Asahi Kasei's process should accelerate the process changing of the monoethylenglycol (MEG) from the conventional EO hydration process.

It is great pleasure for us that the new technology contributes to mankind by practicing Green and Sustainable Chemistry all over the world.

Acknowledgment. In recognition of the outstanding advance in polymer technology, we have received the Award of Society of Polymer Science, Japan (2005). The work of "Development and Industrialization of a novel Process for Polycarbonate Production from $\mathrm{CO}_{2}$ without using Phosgene" has been recognized as an outstanding technology by the other organizations and given several awards, Green and Sustainable Chemistry Award 2002 (Japan's Minister of Economy, Trade and Industry Award) (GSC Network), 35-th Japan Chemical Industry Association Award in 2003, SCEJ Technology Award 2003 (The Society of Chemical Engineers, Japan), Nikkei Global Environment Technology Award in 2004 (Nihon Keizai Shinbun, Inc.), The Chemical Society of Japan Award for Technical Development for 2004, Japan Patent Office Commissioner Award 2005, and The Okochi Memorial Grand Technology Prize 2005 (Okochi Memorial Foundation).

These awards owe to the many persons in Asahi Kasei Group (Asahi Kasei Corp. Asahi Kasei Chemicals Corp., and Asahi Kasei Engineering Corp., all in Japan), Chimei-Asahi Corp. in Taiwan (Joint Venture of Asahi Kasei and Chi Mei) and Chi Mei Group (Chi Mei Corp. and Poly Chemical Engineering Co., both in Taiwan).

We express our grateful acknowledgement to all members who have put their hearts into the development and industrialization of our new process and have led to success.

\section{REFERENCES}

1. a) S. Fukuoka, Chem. Ind., 757 (1997).

b) Eur. Chem. News, 44 (1999).

c) S. Fukuoka, M. Kawamura, K. Komiya, M. Tojo, H. Hachiya, K. Hasegawa, M. Aminaka, H. Okamoto, I. Fukawa, and S. Konno, Green Chem., 5, 497 (2003).

d) S. Fukuoka, Kobunshi, 54, 114 (2005).

e) Kagaku Keizai, 52(6), 100 (2005).

f) S. Fukuoka, 'Green Production Technology' in "Environmental Process Engineering (Japanese)," N. Kojima and K. Sone, The Society of Chemical Engineers, Japan, Ed., Maruzen Co,. Tokyo, 2006, chap. 8.

g) S. Fukuoka, I. Fukawa, M. Kawamura, K. Matsuzaki, and S. Konno, 'The Okochi Memorial Grand Technology Prize: Development and Industrialization of Polycarbonate Production Process Using $\mathrm{CO}_{2}$ as a Raw Material' in "Reports of Achievements in Industrialization Awarded the Okochi Memorial Prize 2005," OKOCHI MEMORIAL FOUNDATION, April 1, 2006, pp 1-15 (Japanese), p 76 (Abstract: English).

2. H. Schnell, L. Bottenbruch, and H. Crimm, Belg. Pat. 532,543 (1954); U.S. Patent 3,028,365 (1962) both assigned to Bayer AG.

3. a) H. Schnell, Angew. Chem., 68, 633 (1956).

b) H. Schnell, Ind. Eng. Chem., 51, 157 (1959).

4. H. Schnell, "Chemistry and Physics of Polycarbonates," Wiley-Interscience, New York, 1964.

5. D. W. Fox, Aust. Patent 221,192 (1959); U.S. Patent 3,153,008 (1964) both assigned to General Electric Co.

6. D. W. Fox and W. Christopher, "Polycarbonates," Reinhold Publishing Corp., New York, 1962.

7. V. Serini, 'Polycarbonates' in "Ullman's Encyclopedia of Industrial Chemistry, Fifth Completely Revised Edition," B. Elvers, S. Hawkins, and G. Schulz, Ed., VCH Verlagsgesellschaft mbH, Weinheim, 1992, vol. A21, p 207.

8. "Polycarbonate Resin Handbook (Japanese)," S. Honma, Ed., Nikkan Kogyo Sinbunsya, Tokyo, 1992, p 1.

9. D. Freitag, U. Grigo, P. R. Mueller, and W. Nouvertne, 'POLYCARBONATES' in "Encyclopedia of Polymer Science and Engineering," H. F. Mark, N. M. Bikales, C. G. Overberger, G. Menges, and J. I. Kroschwitz, Ed., John Wiley \& Sons, New York, 1988, vol. 11, p 648, p 651.

10. P. J. Baker, 'Polymers, Polycarbonate' in "Encyclopedia of Chemical Processing and Design," J. J. Macketta and W. C. Cunningham, Ed., Marcel Dekker, Inc., New York, 1992, vol. 40, p 136, p 138.

11. J. A. King, Jr., 'Synthesis of Polycarbonates' in "Handbook of Polycarbonate Science and Technology," D. G. Legrand and J. T. Bendler, Edt., Marcel Dekker, Inc., New York, 2000, chap. 2, p 9.

12. a) J. E. Hallgren, U.S. Patent 4,096,168 (June 20, 1978) and U.S. Patent 4,201,721 (May 6, 1980), both assigned to General Electric Co.

b) A. J. Chalk, U.S. Patent 4,096,169 (June 20, 1978) and U.S. Patent 4,187,242 (Feb. 5, 1980), both assigned to General Electric Co.

13. a) H. Kezuka and F. Okuda, U.S. Patent 5,336,803 (Aug. 9, 1994), assigned to Idemitsu Kosan Co.

b) R. V. Chaudhari, A. A. Keller, S. P. Gupte, B. M. Bhanage, M. S. Qureshi, B. Moasser, E. J. Pressman, S. Sivaram, C. V. Avadhani, and S. Kanagasabapathy, U.S. Patent 6,222,002 (April 24, 2001), assigned to General Electric Co.

c) K. Okuyama, J. Sugiyama, R. Nagahata, M. Asai, M. Ueda, and K. Takeuchi, Macromolecules, 36, 6953 (2003).

14. D. J. Brunelle, 'POLYCARBONATES' in "Kirk-Othmer Encyclopedia of Chemical Technology, Fifth Edition," A. Seidel, Editor-in-chief, Wiley-Interscience, New Jersey, 2006, vol. 19, p 797, p 815.

15. D. J. Brunelle, 'Advances in Polycarbonate: An Overview' in ACS Symposium Series 898 "Advances in Polycarbonates,” D. J. Brunelle and M. R. Korn, Ed., American Chemi- 
cal Society, Washington, DC, 2005, chap. 1, p 2.

16. For example, a) J. E. Hallgren, G. M. Lucas, and R. O. Matthews, J. Organomet. Chem., 204, 135 (1981).

b) J. E. Hallgren and R. O. Matthews, J. Organomet. Chem., 212, 135 (1981).

c) J. A. King, Jr, T. E. Kraft, and G. R. Faler, U.S. Patent 5,142,086 (Aug. 25, 1992), assigned to General Electric Co. d) E. J. Pressman and J. A. King, Jr, U.S. Patent 5,284,964 (Feb. 8, 1994), assigned to General Electric Co.

e) M. Takagi, H. Miyagi, Y. Ohgomori, and H. Iwane, U.S. Patent 5,498,789 (March 12, 1996), assigned to Mitsubishi Chemical Corp.

f) H.-J. Buysch, J. Dohm, C. Hesse, J. Rechner, and D. Kaufmann, U.S. Patent 5,502,232 (March 26, 1996), assigned to Bayer A.G.

g) E. Yishisato, World Patent WO 99/6142 (Feb. 11, 1999), assigned to Teijin Ltd.

h) C. Hesse, U. Notheis, and J. Rechner, World Patent WO 99/8787 (Feb. 25, 1999), assigned to Bayer A.G.

i) E. J. Pressman, B. F. Johnson, P. O. Moreno, and R. A. Battista, Rechner, World Patent WO 2000/040541 (July 13, 2000), assigned to General Electric Co.

17. a) S. Fukuoka, H. Ogawa, and T. Watanabe, Jap. Patent 1-165551 A1 (Dec. 22, 1987); 7-68178 B1 (July 26, 1995), assigned to Asahi Kasei Chemicals Corp.

b) S. Fukuoka, H. Ogawa, and T. Watanabe, Jap. Patent 8-134022 A1 (Dec. 22, 1987); P2748242 (Feb. 20, 1998), assigned to Asahi Kasei Chemicals Corp.

c) S. Fukuoka, Jap. Patent 4-257646 A1 (Sep. 11, 1992); 7-91237 B1 (Oct. 4, 1995), assigned to Asahi Kasei Chemicals Corp.

d) S. Fukuoka, Jap. Patent 4-261142 A1 (Sep. 17, 1992); 7-68181 B1 (July 26, 1995), assigned to Asahi Kasei Chemicals Corp.

18. K. Nakadai, '6.1.7 Ethylene Oxide, Ethylene Glycol' in "Petrochemical Process (Sekiyu Kagaku Purosesu in Japanese)," Japan Petroleum Institute Ed., Kodansya Scientific Co. 2001, pp 120-125.

19. a) P. P. McClellan, U.S. Patent 2,873,282 (Feb. 10, 1959), assigned to Jefferson Chemical Co.

b) E. Yasui and T. Shibata, Jap. Patent 38-23175 B1 (Oct. 10, 1963), assigned to Toa Gosei. Co.

c) A. H. Emmons, U.S. Patent 3,535,342 (Oct. 20, 1970), assigned to Dow Chemical Co.

d) F. Ohta and S. Tobita, Jap. Patent 48-27314 B1 (Aug. 21, 1973), assigned to Nisso Yuka Co.

e) A. Kato, S. Nagasawa, and T. Noro, Jap. Patent 50-14632 A1 (Feb. 15, 1975), assigned to Toa Gosei Co.

f) 'Ethylene Carbonate and Propylene Carbonate' in "Encyclopedia of Chemical Processing and Design," J. J. McKetta et al., Ed., Marcel Decker, Inc. 1984, Vol. 20, pp. 177-199. g) M. Tojo and S. Fukuoka, Jap. Patent 3-120270 A1 (May 22, 1991); 8-32700 B1 (March 29, 1996), assigned to Asahi Kasei Chemicals Corp.

20. a) L. K. Frevel and J. A. Gilpin, U.S. Patent 3,642,858 (Feb. 15, 1972), assigned to Dow Chemical Co.

b) H.-J. Buysch, H. Krimm, and H. Rudolph, U.S. Patent 4,181,676 (Jan. 1, 1980), assigned to Bayer AG.

c) S. W. King and B. C. Ream, Eur. Patent 0478073 A2
(April 1, 1992), assigned to Union Carbide Chemicals \& Plastics Co.

21. U. Romano and U. Melis, U.S. Patent 4,062,884 (Dec. 13, 1977), assigned to ANIC, S.p.A.

22. a) R. G. Duranleau, E. C. Y. Nieh, and J. F. Knifton, U.S. Patent 4,691,041 (Sep. 1, 1987), assigned to Texaco Inc. b) J. F. Knifton and R. G. Duranleau, J. Mol. Cat., 1991, 67, 389.

23. a) S. Fukuoka, Y. Sasaki, and M. Tojo, Jap. Patent 4-198141 A1 (July 17, 1992) (Application: Nov. 29, 1990); P2529025 (June 14, 1996), assigned to Asahi Kasei Chemicals Corp. b) About 8 months later, an analogous U.S. Patent was applied. H.-J. Buysch, A. Klausener, and F.-J. Mais, U.S. Patent 5,231,212 (July 27, 1993) (Foreign Application Priority: Sep. 3, 1991), assigned to Bayer AG.

c) M. Tojo and S. Fukuoka, Jap. Patent 63-238043 A1 (Oct. 4, 1988); 7-37422 B2 (April 26, 1995), assigned to Asahi Kasei Chemicals Corp.

d) H. Minoura and H. Nakajima, Jap. Patent 3-109358 A1 (May 9, 1991); P2955866 (July 23, 1999), assigned to Asahi Kasei Chemicals Corp.

e) M. Tojo and S. Fukuoka, Jap. Patent 4-9356 A1 (Jan. 14, 1992); 7-91232 B2 (Oct. 4, 1995), assigned to Asahi Kasei Chemicals Corp.

f) Y. Sasaki, K. Komiya, and S. Fukuoka, Jap. Patent 4-54156 A1 (Feb. 21, 1992); 7-91233 B2 (Oct. 4, 1995), assigned to Asahi Kasei Chemicals Corp.

g) Y. Sasaki, K. Komiya, and S. Fukuoka, Jap. Patent 4-103561 A1 (April 6, 1992); 7-110840 B2, P2086543 (Sep. 2, 1996), assigned to Asahi Kasei Chemicals Corp.

h) S. Fukuoka, Y. Sasaki, and M. Tojo, Jap. Patent 4-198141 A1 (July 17, 1992); P2529025 (June 14, 1996), assigned to Asahi Kasei Chemicals Corp.

i) S. Fukuoka, M. Tojo, and Y. Sasaki, Jap. Patent 4-230243 A1 (Aug. 19, 1992); 7-68180 B2 (July 26, 1995), assigned to Asahi Kasei Chemicals Corp.

j) S. Fukuoka and K. Komiya, Jap. Patent 5-78284 A1 (March 30, 1993); P3016289 (Dec. 24, 1999), assigned to Asahi Kasei Chemicals Corp.

k) H. Okamoto and S. Fukuoka, Jap. Patent 6-16596 A1 (Jan. 25, 1994); P3214576 (July 27, 2001), assigned to Asahi Kasei Chemicals Corp.

1) M. Tojo, S. Fukuoka, and M. Kawamura, Jap. Patent 9-183744 A1 (July 15, 1997); P3652035 (March 4, 2005), assigned to Asahi Kasei Chemicals Corp.

m) M. Tojo, S. Fukuoka, and M. Kawamura, Jap. Patent 9-194435 A1 (July 29,1997), assigned to Asahi Kasei Chemicals Corp.

n) M. Tojo, S. Fukuoka, and M. Kawamura, World Patent WO 97/23445 A1 (July 3, 1997); U.S. Patent 5.847,189 (Dec. 8, 1998), Eur. Patent 0889025 B1 (April 3, 2002), all assigned to Asahi Kasei Chemicals Corp.

o) M. Tojo, S. Fukuoka, and M. Kawamura, Jap. Patent 9-176061 A1 (Dec. 28, 1995), assigned to Asahi Kasei Chemicals Corp.

p) S. Kawazoe and M. Tojo, Jap. Patent 9-221436 A1 (Feb. 14, 1996); P3773294 (Feb. 24, 1996), assigned to Asahi Kasei Chemicals Corp.

q) M. Tojo and K. Onishi, World Patent WO 99/64382 
(Dec. 16, 1999); U.S. Patent 6,346,638 B1 (Feb. 12, 2002), assigned to Asahi Kasei Chemicals Corp.

r) M. Tojo, K. Onishi, and K. Tomoyasu, Jap. Patent 2002308804 A1 (Oct. 23, 2002), assigned to Asahi Kasei Chemicals Corp.

s) M. Tojo and K. Onishi, U.S. Patent 6,479,689 B1 (Nov. 12, 2002), assigned to Asahi Kasei Chemicals Corp. t) M. Tojo and H. Miyaji, World Patent WO 2005/123638 (Dec. 29, 2005), assigned to Asahi Kasei Chemicals Corp.

24. a) M. M. Mauri, U. Romano, and F. Rivetti, ING. CHIM. ITAL., 21, N. 1-3, GEN-MAR, 6 (1985).

b) F. Rivetti, U. Romano, G. Garone, and M. Ghirardini, U.S. Patent 5,527,943 (June 18, 1996), assigned to Enichem Synthesis S.p.A.

c) U. Romano, R. Tessel, G. Cipriani, and L. Micucci, U.S. Patent 4,218,391 (Aug. 19, 1980), assigned to ANIC, S.p.A. d) U. Romano, F. Rivetti, and N. D. Muzio, U.S. Patent 4,318,862 (Mar. 9, 1982), assigned to ANIC, S.p.A.

25. a) T. Matsuzaki, Syokubai (Catalysis), 41, 53 (1999).

b) M. Misono, Kagaku Keizai, 49(11), 38 (2002).

26. a) E. P. Boden, G. Kailasam, L. N. Lewis, and I. Vic Fernandez, World Patent WO 03/016256 (Feb. 27, 2003), assigned to General Electric Comp.

b) E. P. Boden and Vic Fernandez, World Patent WO 03/016258 (Feb. 27, 2003), assigned to General Electric Comp.

27. P. Tundo, F. Trotta, G. Moraglio, and F. Ligorati, Ind. Eng. Chem. Res., 27, 1565 (1988).

28. a) S. Fukuoka, M. Tojo, and M. Kawamura, World Patent WO 91/09832 A1 (July 11, 1991) (Priority: Dec. 28, 1989), assigned to Asahi Kasei Chemicals Corp.

b) S. Fukuoka, M. Tojo, and M. Kawamura, Jap. Patent 4-224547 A1 (Aug. 13, 1992); 7-91234 B2 (Oct. 4, 1995), assigned to Asahi Kasei Chemicals Corp.

29. a) G. Illuminati, U. Romano, and R. Tesei, U.S. Patent 4,182,726 (Jan. 8, 1980), assigned to Snamprogetti, S.p.A.

b) Y. Harano and T. Mitani, Jap. Patent 61-291545A1 (Dec. 22, 1986); 62-8091 B1 (Feb. 20, 1987), assigned to Daicel Chemical Co.

c) V. Mark, U.S. Patent 4,554,110 (Nov. 19, 1985), assigned to General Electric Co.

d) V. Mark, U.S. Patent 4,552,704 (Nov. 12, 1985), assigned to General Electric Co.

e) V. Mark, U.S. Patent 4,609,501 (Sep. 2, 1986), assigned to General Electric Co.

f) H. Krimm, H.-J. Buysch, and H. Rudolph, Eur. Patent 0 000879 A1 (March 7, 1979), assigned to Bayer AG.

g) H. Krimm, H.-J. Buysch, and H. Rudolph, U.S. Patent 4,252,737 (Feb. 24, 1981), assigned to Bayer AG.

h) H.-J. Buysch, N. Schon, and J. Rechner, U.S. Patent 5,284,965 (Feb. 8, 1994), assigned to Bayer AG.

i) Y. Kiso and Y. Matsunaga, U.S. Patent 5,034,557 (July 23, 1991), assigned to Mitsui Petrochemical Ind.

j) T. Onoda, K. Tano, and Y. Hara, Jap. Patent 61-5467 B1 (Feb. 18, 1986), assigned to Mitsubishi Chemical Co.

k) E. Yoshisato and T. Yoshitomi, Jap. Patent 9-59209 A1 (March 4, 1997), assigned to Teijin Ltd.

30. J. E. Hallgren, U.S. Patent 4,410,464 (Oct. 18, 1983), assigned to General Electric Co.
31. a) N. Schon, R. Langer, and H.-J. Buysch, U.S. Patent 5,334,742 (Aug. 2, 1994) (Priority Application: Aug. 13, 1992), assigned to Bayer AG.

b) N. Schon, R. Langer, H.-J. Buysch, P. Wagner, and R. Langer, U.S. Patent 5,344,954 (Sep. 6, 1994) (Priority Application: Aug. 13, 1992), assigned to Bayer AG.

c) R. Paludetto, G. Paret, G. Donatti, and F. Rivetti, Ital. Patent 01255746 (Nov. 15, 1995) (Application April 1, 1992), assigned to Enichem Synthesis S.p.A.

d) F. Rivetti, R. Paludetto, and U. Romano, U.S. Patent 5,705,673 (Jan. 6, 1998), (Priority Application: Jan. 16, 1996) assigned to Enichem S.p.A.

e) M. H. Oyevaar, B. W. To, M. F. Doherty, and M. F. Malone, U.S. Patent 6,093,842 (July 25, 2000), assigned to General Electric Co.

f) M. Inaba, K. Hasegawa, and K. Sawa, Jap. Patent 9-40616 A1 (Feb. 10, 1997), assigned to Mitsubishi Chemical Co. g) M. Inaba, K. Sawa, and T. Tanaka, Jap. Patent 9-59225 A1 (March 4, 1997), assigned to Mitsubishi Chemical Co. h) M. Inaba, K. Sawa, and T. Tanaka, Jap. Patent 9-110805 A1 (April 28, 1997), assigned to Mitsubishi Chemical Co. i) H. Tsuneki, Y. Onda, A. Moriya, and H. Yoshida, Eur. Patent 0684221 A1 (Nov. 29, 1995), assigned to Nippon Syokubai Co.

j) H. Kudoh, H. Kobayasi, T. Minami, K. Kaeruishi, K. Shimogawara, and K. Ajimura, Jap. Patent 2001-64234 A1 (March 13, 2001), assigned to Chiyoda Kako Co.

k) H. Kudoh, H. Kobayasi, T. Minami, K. Kaeruishi, K. Ajimura, and K. Shimogawara, Jap. Patent 2001-64235 A1 (March 13, 2001), assigned to Chiyoda Kako Co.

1) S. M. Bouwens and M. Vieveen, U.S. Patent $6,596,894$ (July 22, 2003), assigned to General Electric Co.

m) S. M. Bouwens and M. Vieveen, U.S. Patent 6,596,895 (July 22, 2003), assigned to General Electric Co.

n) S. M. Bouwens and M. Vieveen, U.S. Patent $6,600,061$ (July 29, 2003), assigned to General Electric Co.

32. a) T. Watanabe and S. Fukuoka, Jap. Patent 57-176932 A1 (Dec. 30, 1981); 64-3181B2 (Jan. 19, 1989), assigned to Asahi Kasei Chemicals Corp.

b) T. Watanabe and S. Fukuoka, Jap. Patent 57-183745 A1 (May 6, 1981); 64-5588 B2 (Jan. 31, 1989), assigned to Asahi Kasei Chemicals Corp.

c) S. Fukuoka, R. Deguchi, and M. Tojo, U.S. Patent 5,166,393 (Nov. 24, 1992); Jap. Patent 1-93560 A1 (April 12, 1989); 5-44938 B2 (July 7, 1993), assigned to Asahi Kasei Chemicals Corp.

d) S. Fukuoka and R. Deguchi, Jap. Patent 3-200746 A1 (Sep. 2, 1991); 7-91230 B2 (Oct. 4, 1995), assigned to Asahi Kasei Chemicals Corp.

e) S. Fukuoka and R. Deguchi, Jap. Patent 3-236354 A1 (Oct. 22, 1991); 7-91231 B2 (Oct. 4, 1995), assigned to Asahi Kasei Chemicals Corp.

f) S. Fukuoka, M. Tojo, and M. Kawamura, Jap. Patent 3-291257 A1 (Dec. 20, 1991) (Priority Dec. 28, 1989); 7-91236 B2 (Oct. 4, 1995), assigned to Asahi Kasei Chemicals Corp.

g) S. Fukuoka, M. Tojo, and M. Kawamura, Jap. Patent 49358 A1 (Jan. 14, 1992) (Priority Dec. 28, 1989); 7-91235 B2 (Oct. 4, 1995), assigned to Asahi Kasei Chemicals Corp. 
h) S. Fukuoka, M. Tojo, and M. Kawamura, Jap. Patent 4-211038 A1 (Aug. 3, 1992) (Priority Feb. 21, 1990); 7-68182 B2 (July 26, 1995), assigned to Asahi Kasei Chemicals Corp.

i) S. Fukuoka, M. Tojo, and M. Kawamura, U.S. Patent 5,210,268 (May 11, 1993); Eur. Patent 461274 B1 (June 15, 1994), assigned to Asahi Kasei Chemicals Corp.

j) S. Fukuoka, M. Tojo, and M. Kawamura, Jap. Patent 4-224547 A1 (Dec. 26, 1990); 7-91234 B2, assigned to Asahi Kasei Chemicals Corp.

k) S. Fukuoka, M. Tojo, and M. Kawamura, Jap. Patent 4-230242 A1 (Aug. 19, 1992); 7-68179 B2 (July 26, 1985), assigned to Asahi Kasei Chemicals Corp.

1) S. Fukuoka, M. Tojo, and M. Kawamura, Jap. Patent 4-235951 A1 (Aug. 25, 1992); 7-72158 B2 (Aug. 2, 1995), assigned to Asahi Kasei Chemicals Corp.

m) K. Komiya, M. Tojo, and S. Fukuoka, World Patent WO 97/11049 (March 27, 1997) (Priority Sept. 22, 1995); Eur. Patent 0855384 A1 (July 29, 1998); U.S. Patent., 5,872,275; Jap. Patent P3204983 (June 29, 2001), assigned to Asahi Kasei Chemicals Corp.

n) M. Tojo, K. Onishi, and K. Komiya, Jap. Patent 11-92429 A1 (April 6, 1999); World Patent WO 99/14183 (March 25, 1999) (Priority Sept. 16, 1997); Eur. Patent 1016648 A1 (July 5, 2000), assigned to Asahi Kasei Chemicals Corp. o) M. Tojo and H. Miyaji, World Patent WO 2005/123657 (Dec. 29, 2005), assigned to Asahi Kasei Chemicals Corp. p) S. Fukuoka, H. Hachiya, and K. Matsuzaki, World Patent WO 2006/001256 (Jan. 5, 2006), assigned to Asahi Kasei Chemicals Corp.

q) S. Fukuoka, H. Hachiya, and K. Matsuzaki, World Patent WO 2006/001257 (Jan. 5, 2006), assigned to Asahi Kasei Chemicals Corp.

r) S. Fukuoka, H. Hachiya, and K. Matsuzaki, World Patent WO 2006/006566 (Jan. 19, 2006), assigned to Asahi Kasei Chemicals Corp.

s) S. Fukuoka, H. Hachiya, and K. Matsuzaki, World Patent WO 2006/006568 (Jan. 19, 2006), assigned to Asahi Kasei Chemicals Corp.

t) S. Fukuoka, H. Hachiya, and K. Matsuzaki, World Patent WO 2006/006585 (Jan. 19, 2006), assigned to Asahi Kasei Chemicals Corp.

u) S. Fukuoka, H. Hachiya, and K. Matsuzaki, World Patent WO 2006/006588 (Jan. 19, 2006), assigned to Asahi Kasei Chemicals Corp.

v) S. Fukuoka, H. Miyaji, H. Hachiya, and K. Matsuzaki, World Patent WO 2006/022294 (March 2, 2006), assigned to Asahi Kasei Chemicals Corp.

w) S. Fukuoka, H. Miyaji, H. Hachiya, and K. Matsuzaki, World Patent WO 2006/025424 (March 9, 2006), assigned to Asahi Kasei Chemicals Corp.

x) S. Fukuoka, H. Miyaji, H. Hachiya, and K. Matsuzaki, World Patent WO 2006/025478 (March 9, 2006), assigned to Asahi Kasei Chemicals Corp.

y) S. Fukuoka, H. Miyaji, H. Hachiya, and K. Matsuzaki, World Patent WO 2006/030724 (March 23, 2006), assigned to Asahi Kasei Chemicals Corp.

z) S. Fukuoka, H. Miyaji, H. Hachiya, and K. Matsuzaki, World Patent WO 2006/033288 (March 30, 2006), assigned to Asahi Kasei Chemicals Corp.

aa) S. Fukuoka, H. Miyaji, H. Hachiya, and K. Matsuzaki, World Patent WO 2006/0233291 (March 30, 2006), assigned to Asahi Kasei Chemicals Corp.

bb) S. Fukuoka, H. Miyaji, H. Hachiya, and K. Matsuzaki, World Patent WO 2006/035642 (April 6, 2006), assigned to Asahi Kasei Chemicals Corp.

cc) S. Fukuoka, H. Miyaji, H. Hachiya, and K. Matsuzaki, World Patent WO 2006/041025 (April 20, 2006), assigned to Asahi Kasei Chemicals Corp.

dd) S. Fukuoka, H. Miyaji, H. Hachiya, and K. Matsuzaki, World Patent WO 2006/043491 (April 27, 2006), assigned to Asahi Kasei Chemicals Corp.

33. K. Komiya, S. Fukuoka, M. Aminaka, K. Hasegawa, H. Hachiya, H. Okamoto, T. Watanabe, H. Yoneda, I. Fukawa, and T. Dozono, 'New Process for Producing Polycarbonate Without Phosgene and Methylene Chloride' in "Green Chemistry Designing Chemistry for the Environment," ACS Symposium Series 626, P. Anastas and T. C. Williamson, Ed., American Chemical Society, Washington, DC, 1996, chap. 2.

34. a) P. J. Flory, U.S. Patent 2,172,374 (Sep. 12, 1939), assigned to E. I. DuPont Co.

b) H. J. Hagemeyer, Jr., U.S. Patent 3,043,808 (July 10, 1962), assigned to Eastman Kodak Co.

35. a) S. Fukuoka, T. Watanabe, and T. Dozono, Jap. Patent 1-158033 A1 (June 21, 1989) (Priority Sept. 28, 1987); 7-94546 B2 (Oct. 11, 1995); World Patent WO 89/02904 (April 6, 1989); U.S. Patent 4,948,871 (Aug. 14, 1990); Eur. Pat 0338085 B1 (June 22, 1994), assigned to Asahi Kasei Corp.

b) I. Fukawa, S. Fukuoka, K. Komiya, and Y. Sasaki, Jap. Patent 3-223330 (Oct. 2, 1991) (Priority March 28, 1989); P2546724 (Aug. 8, 1996).

c) I. Fukawa, S. Fukuoka, K. Komiya, and Y. Sasaki, U.S. Patent 5,204,377 (Apr. 20, 1993); Eur. Patent 0403657 B1 (Jan. 28, 1998), to Asahi Kasei Corp.

d) I. Fukawa, S. Fukuoka, K. Komiya, and Y. Sasaki, U.S. Patent 5,214,073 (May 25, 1993), to Asahi Kasei Corp.

e) K. Komiya, S. Fukuoka, and A. Yamaguchi, Jap. Patent 4-72326 A1 (March 6, 1992); 7-86138 B1 (Sept. 20, 1995), to Asahi Kasei Corp.

f) K. Komiya, Jap. Patent 6-271659 A1 (Sep. 27, 1994); P3208210 (July 6, 2001), to Asahi Kasei Corp.

36. a) S. Sivaram, J. C. Sehra, V. S. Iyer, and K. Ravindranath, U.S. Patent 5,266,659 (Nov. 30, 1993); S. Sivaram and S. B. Halt, Eur. Patent 0801089 A1 (Oct. 15, 1997), and Eur. Patent 09080483 A1 (April 14, 1999), all assigned to Council of Scientific \& Industrial Research, India.

b) B. B. Idage, S. Sivaram, G. S. Varadarajan, and J. A. King, Jr., U.S. Patent 5,717,056 (Feb. 10, 1998) and U.S. Patent 5,905,135 (May 18, 1999), Eur. Patent 0949288 A1 (Oct. 13, 1999); S. Sivaram and S. B. Halt, U.S. Patent 5,710,238 (Jan. 20, 1998), all assigned to General Electric Co.

c) R. Hisanishi and M. Okamura, Jap. Patent 6-228299 A1 (Aug. 16, 1994); S. Kuze, K. Tanaka, A. Shishikura, and R. Hisanishi, Jap. Patent 9-235368 A1 (Sep. 9, 1997); S. Kuze and K. Tanaka, Jap. Patent 10-7785 A1 (Jan. 13, 
1998); S. Kuze, M. Ito, and Y. Ishikawa, Jap. Patent 10130384 A1 (May 19, 1998); M. Ito, Jap. Patent 11-217430 (Aug. 10, 1999); Jap. Patent 11-236444 A1 (Aug. 31, 1999); M. Ito, World Patent WO 99/26995 A1 (June 3, 1999); M. Okamoto and M. Ito, World Patent WO 99/ 36458 A1 (July 22, 1999); M. Ito and S. Kuze, World Patent WO 99/48947 A1 (Sep. 30, 1999); M. Ito, Jap. Pat., 2001247671 A1 (Sep. 11, 2001), 2002-155162 A1 (May 28, 2002) and 2002-220456 A1 (Aug. 9, 2002); M. Ito and A. Shishikura, Jap. Patent 2002-241484 A1 (Aug. 28, 2002), all assigned to Idemitsu Petrochemical Co.

d) M. G. Ormand and S. Munjal, U.S. Patent 5,864,006 (Jan. 26, 1999), assigned to Dow Chemical Co.

e) K. Matsumoto, Jap. Patent 6-322097 A1 (Nov. 22, 1994); T. Sakurai and N. Kido, Jap. Patent 2001-247670 A1 and 2001-247672 A1 (Sep. 11, 2001), all assigned to Teijin Ltd. f) V. S. Iyer, J. C. Sehra, K. Ravindranath, and S. Sivararam, Macromolecules, 26, 1186 (1993).

g) S. M. Gross, G. W. Roberts, D. J. Kiserow, and J. M. DeSimone, Macromolecules, 34, 3916 (2001).

37. a) K. Tominari, A. Kanazawa, and Y. Shigeta, Jap. Patent 2-153923 A1; 2-153924 A1; 2-153925 A1; 2-193926 A1; and 2-193927 A1 (all June 13, 1990), all assigned to GE Plastics Japan Co.

b) M. Kimura, H. Nakano, M. Nakajima, and K. Hayashi, Jap. Patent 2000-159879 A1 and 2000-159880 A1 (all June 13, 2000), all assigned to Mitsubishi Chemical Co. and Mitsubishi Gas Chemical Co.

c) T. Tayama, M. Kawai, K. Hayashi, and T. Kawakami, Jap. Patent 2000-178354 A1 (June 27, 2000), assigned to Mitsubishi Chemical Co. and Mitsubishi Gas Chemical Co.

38. a) I. Fukawa and T. Tanabe, Jap. Patent 3-252421 A1 (Nov. 11, 1991); 7-98862 B2 (Oct. 25, 1995), assigned to Asahi Kasei Chemicals Corp.

b) K. Komiya, M. Aminaka, and Y. Kawakami, Jap. Patent 8-225641 A1 (Sep. 13, 1996), assigned to Asahi Kasei Chemicals Corp.

c) H. Hachiya and K. Komiya, Jap. Patent 8-231844 A1 (Sept. 10, 1996); P3393167 (Jan. 24, 2003), assigned to Asahi Kasei Chemicals Corp.

d) K. Komiya, S. Fukuoka, and Y. Kawakami, Jap. Patent 8-325372 A1, 8-325373 A1 (Nov. 10, 1996), assigned to Asahi Kasei Chemicals Corp.

e) K. Komiya, Y. Kawakami, and H. Okamoto, Eur. Patent 0 710687 B1 (Nov. 11, 2001), assigned to Asahi Kasei Chemicals Corp.

f) K. Komiya, Y. Kawakami, and H. Okamoto, U.S. Patent 5,589,564 (Dec. 31, 1996), assigned to Asahi Kasei Chemicals Corp.

g) K. Komiya, Y. Kawakami, and H. Okamoto, U.S. Patent 5,596,067 (Jan. 21, 1997), assigned to Asahi Kasei Chemicals Corp.

h) K. Komiya, K. Hasegawa, and S. Fukuoka, Jap. Patent 6-56984 A1 (March 1, 1994); P3100008 (Aug. 18, 2000), assigned to Asahi Kasei Chemicals Corp.

i) K. Komiya, K. Hasegawa, and M. Aminaka, Jap. Patent 10-330474 A1 (Dec. 15, 1998); P2989578 (Oct. 8, 1999), assigned to Asahi Kasei Chemicals Corp.

j) K. Komiya, S. Fukuoka, and M. Kawamura, Jap. Patent
P3202993 (June 22, 2001); World Patent WO 97/22650 (June 26, 1997); U.S. Patent 5,840,826 (Nov. 24, 1998); Eur. Pat 0867459 B1 (March 10, 2004), assigned to Asahi Kasei Chemicals Corp.

k) K. Komiya and S. Fukuoka, Jap. Patent 9-255772 (Sep. 30, 1997): P3724905 (Sep. 30, 2005); U.S. Patent 5,747,609 (May 5, 1998); Eur. Pat 0892001 B1 (Aug. 7, 2002), assigned to Asahi Kasei Chemicals Corp.

1) K. Komiya and S. Fukuoka, Jap. Patent U.S. Patent 6,429,276 (Aug. 6, 2002); Eur. Pat 1048685 B1 (Dec. 14, 2005), assigned to Asahi Kasei Chemicals Corp.

m) K. Komiya, S. Fukuoka, M. Aminaka, and K. Hasegawa, Jap. Patent P3577695 (July 23, 2004); U.S. Patent 6,320,015 (Nov. 20, 2001); Eur. Pat 1095957 B1 (June 16, 2004), assigned to Asahi Kasei Chemicals Corp.

n) S. Fukuoka, H. Hachiya, and K. Matsuzaki, World Pat WO 2005/121210 (Dec. 22, 2005), assigned to Asahi Kasei Chemicals Corp.

o) S. Fukuoka, H. Hachiya, and K. Matsuzaki, World Patent WO 2005/121211 (Dec. 22, 2005), assigned to Asahi Kasei Chemicals Corp.

p) S. Fukuoka, H. Hachiya, and K. Matsuzaki, World Patent WO 2005/123805 (Dec. 29, 2005), assigned to Asahi Kasei Chemicals Corp.

q) S. Fukuoka, H. Hachiya, and K. Matsuzaki, World Patent WO 2006/064656 (June 22, 2006), assigned to Asahi Kasei Chemicals Corp.

r) S. Fukuoka, H. Hachiya, and K. Matsuzaki, World Patent WO 2006/064664 (June 22, 2006), assigned to Asahi Kasei Chemicals Corp.

s) S. Fukuoka, H. Hachiya, and K. Matsuzaki, World Patent WO 2006/064667 (June 22, 2006), assigned to Asahi Kasei Chemicals Corp.

t) S. Fukuoka, H. Hachiya, and K. Matsuzaki, World Patent WO 2006/067993 (June 29, 2006), assigned to Asahi Kasei Chemicals Corp.

u) S. Fukuoka, H. Hachiya, and K. Matsuzaki, World Patent WO 2006/067994 (June 29, 2006), assigned to Asahi Kasei Chemicals Corp.

39. P. T. Anastas and J. C. Warner, "Green Chemistry: Theory and Practice," Oxford University Press, Oxford, 1998.

40. The newspapers say that the construction costs of the PC production new plants are as follows:

(a) Phosgene process

(i) About 20 thousand million yen ( $¥$ ) for 60,000 ton/year plant of "T. Co." in Singapore. Sekiyu-Kagaku-Shinbun (Japanese) [The "Petro-Chemical Press" (weekly)], Dec. 6, 1999.

(ii) About 20 thousand million $¥$ for 40,000 ton/year plant of “S.D. Co." in Japan. Kagaku Kogyo Nippo (Japanese) [The Chemical Daily], Oct. 7, 1993.

(b) Non-phosgene Asahi Kasei process

About 9 thousand million yen ( $¥$ ) for 50,000 ton/year plant of Chimei-Asahi Corp. in Taiwan. Kagaku Kogyo Nippo (Japanese) [The Chemical Daily], Nov. 8, 1999.

41. In the Asahi Kasei process, all raw materials (EO, $\mathrm{CO}_{2}$ and Bis-A) are converted to the products (PC and MEG). The cost for purchasing EO can be fully covered by selling the monoethyleneglycol (MEG). This is reasonable because 
GSC in Practice: Novel Non-Phosgene PC Production Process from $\mathrm{CO}_{2}$

MEG is the product and EO is the raw material and the price of the product is usually higher than the price of the raw material. The $\mathrm{CO}_{2}$ is also by-product emitted into the atmosphere at EO production step. However, in the phosgene process, $\mathrm{Cl}_{2}$ and $\mathrm{NaOH}$ (raw materials) are wasted as $\mathrm{NaCl}$. At least this point shows that Asahi Kasei Process is more economical than the phosgene process.

42. European Chemical News (ECN) describes our process in the article of Polycarbonate" July 2002/Process Review pp. 32-34, the extraction is as follows:

"Phosgene is a toxic chemical that requires rigorous process design standards to protect the health and safety of workers. Investment requirements are increased by the need for close analytical monitoring and control, equipment designs for lethal service, and treatment of vent streams by caustic scrubbing or incineration. Toughening of environmental restrictions worldwide has added impetus to the search for non-phosgene routes to polycarbonate.
In addition to phosgene concerns, the interfacial polymerization process typically uses a chlorinated solvent, methylene chloride, another material with exposure limits. A further incentive to eliminate the use of phosgene is the economic penalty incurred because the chlorine content of the phosgene is wasted and converted to sodium chloride. Caustic soda is consumed in the conversion, and the disposal of waste salt solutions presents ecological problems in itself. In a second stage reactor, the ethylene carbonate is transesterified with methanol to give two products-dimethyl carbonate and ethylene glycol. Since a large portion of ethylene oxide is normally converted to ethylene glycol for use in polyester production, this approach in essence converts methanol to dimethyl carbonate with virtually no addition raw material costs. And, as an extra bonus, selectivity to ethylene glycol is very high, avoiding diethylene glycol and triethylene glycol, which are by-products of conventional ethylene glycol processes via hydrolysis of ethylene oxide."

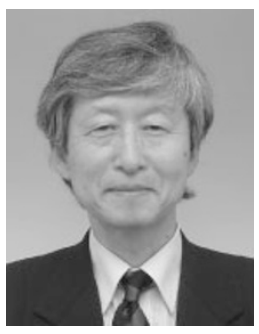

Dr. Shinsuke Fukuoka was born in Osaka Prefecture, Japan in 1943. He received his B.S. degree in 1966 from Osaka University and his Doctoral degree of Engineering in 1971 from Osaka University under the supervision of late Professor Shigeru Tsutsumi. He joined Asahi Chemical Industry Co. (Japan) in 1971. He was engaged in the R \& D of aromatic polyamides and spinning thereof, and a plastic optical fiber in Fiber Development Laboratory from 1971 to 1978 . From 1977, he by oneself had started the thorough investigation of the prior arts and the basic research for developing a non-phosgene process for polycarbonate. He was transferred to Petrochemical Research Laboratory in 1979, since then, he had led the R \& D of the non-phosgene processes for producing PC or isocyanates (MDI, HDI) until 2000. He was a general manager of Chemistry \& Chemical Process Laboratory (19921995). Then, he became the general manager of the project for developing the non-phosgene PC process, which project had to establish the technology enabling the industrialization in a foreign country at pilot stage (19952000). He was a recipient of Green and Sustainable Chemistry Award 2002 (Japan's Minister of Economy, Trade and Industry Award) (GSC Network), 35-th Japan Chemical Industry Association Award in 2003, Nikkei Global Environment Technology Award in 2004 (Nihon Keizai Shinbun, Inc.), The Chemical Society of Japan Award for Technical Development for 2004, Japan Patent Office Commissioner Award 2005, The Okochi Memorial Grand Technology Prize 2005 (Okochi Memorial Foundation) and The Award of the Society of Polymer Science, Japan (2005). He is the author and coauthor of $c a .30$ original papers, reviews and books, and $c a .850$ patents.

Masahiro Tojo was born in Nagoya, Japan in 1955. He received his master degree from Faculty of Science, Kyoto University in 1980. In the same year he joined Asahi Chemical Industry Co. and started his R \& D at Petrochemical Research Laboratory. He has been mainly engaged in the R \& D of producing process of various chemicals. He was engaged in the development of DMC and DPC production process from flask scale research to pilot stage (19851990, 1995-2000). He is currently a group leader at Central Research and Development Laboratories. His current research interests include syntheses of organic functional materials and process chemistry. He was a recipient of Green and Sustainable Chemistry Award 2002 (Japan's Minister of Economy, Trade and Industry Award) (GSC Network), 35-th Japan Chemical Industry Association Award in 2003, Nikkei Global Environment Technology Award in 2004 (Nihon Keizai Shinbun, Inc.) and The Award of the Society of Polymer Science, Japan (2005). 


\section{S. FUKUOKA et al.}
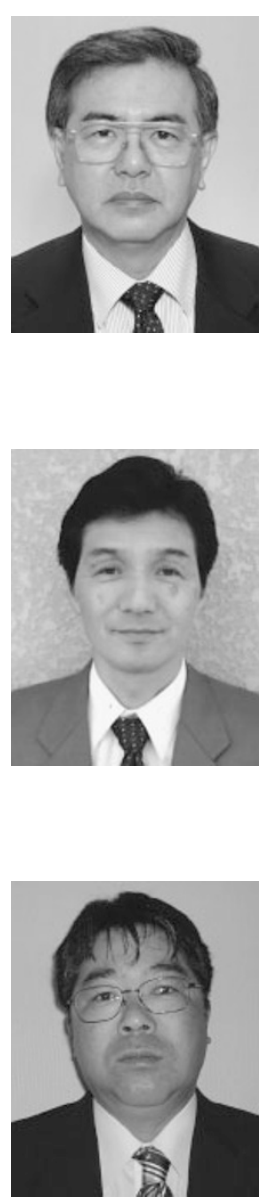

Dr. Hirosi Hachiya was born in Saga Prefecture, Japan in 1954. He received his Doctoral degree of Engineering in 2000 from Shibaura Institute of Technology under the supervision of Professor Kunihiko Takeda. He joined Asahi Chemical Industry Co. (Japan) in 1975. Since then he has been mainly engaged in the R \& D of polymeric materials such as polyolefins (1975-1985), aromatic polyether ketones (1985-1990) and aromatic polycarbonate (19862000). After establishing the products technology of the PC, which is inevitable for the commercial products, he is currently a group leader at Technology Licensing Department. He was a recipient of 35-th Japan Chemical Industry Association Award in 2003, Nikkei Global Environment Technology Award in 2004 (Nihon Keizai Shinbun, Inc.) and The Award of the Society of Polymer Science, Japan (2005).

Muneaki Aminaka was born in Tokyo, Japan in 1954. He graduated Tokyo National College of Technology in 1975. He joined Asahi Chemical Industry Co. (Japan) in 1975. Since then he has been mainly engaged in the R \& D of polymer production process such as polyacetals (1975-1985), aromatic polyether ketones (1985-1986) and aromatic polycarbonate (1986-2000). After establishing the new polymerization process for PC at the pilot stage, he became a member of the construction and operation technology transfer group for the PC plant in Taiwan (2000-2002). He was a recipient of Nikkei Global Environment Technology Award in 2004 (Nihon Keizai Shinbun, Inc.), Japan Patent Office Commissioner Award 2005 and The Award of the Society of Polymer Science, Japan (2005).

Kazumi Hasegawa was born in Kagawa Prefecture, Japan in 1953. He graduated Ube Technical High School in 1972. He joined Asahi Chemical Industry Co. (Japan) in 1972. He was engaged in the operating of HDPE plant until 1975. After that he has been engaged in the R \& D of several fields such as catalysts for HDPE and LLDPE, new polymerization methods for aromatic polyether ketones, atomizing of metals. From 1986, he had been engaged in the development of PC at the bench and pilot stages. He was one of the main members who established the new PC process at pilot stage. He was a member of the construction and operation technology transfer group for the PC plant (2000-2002). He was a recipient of Nikkei Global Environment Technology Award in 2004 (Nihon Keizai Shinbun, Inc.), Japan Patent Office Commissioner Award 2005 and The Award of the Society of Polymer Science, Japan (2005). 